Cochrane Database of Systematic Reviews

\title{
Ganoderma lucidum (Reishi mushroom) for cancer treatment
} (Review)

Jin X, Ruiz Beguerie J, Sze DMY, Chan GCF

Jin X, Ruiz Beguerie J, Sze DMY, Chan GCF.

Ganoderma lucidum (Reishi mushroom) for cancer treatment.

Cochrane Database of Systematic Reviews 2016, Issue 4. Art. No.: CD007731.

DOI: 10.1002/14651858.CD007731.pub3.

www.cochranelibrary.com 
TABLE OF CONTENTS

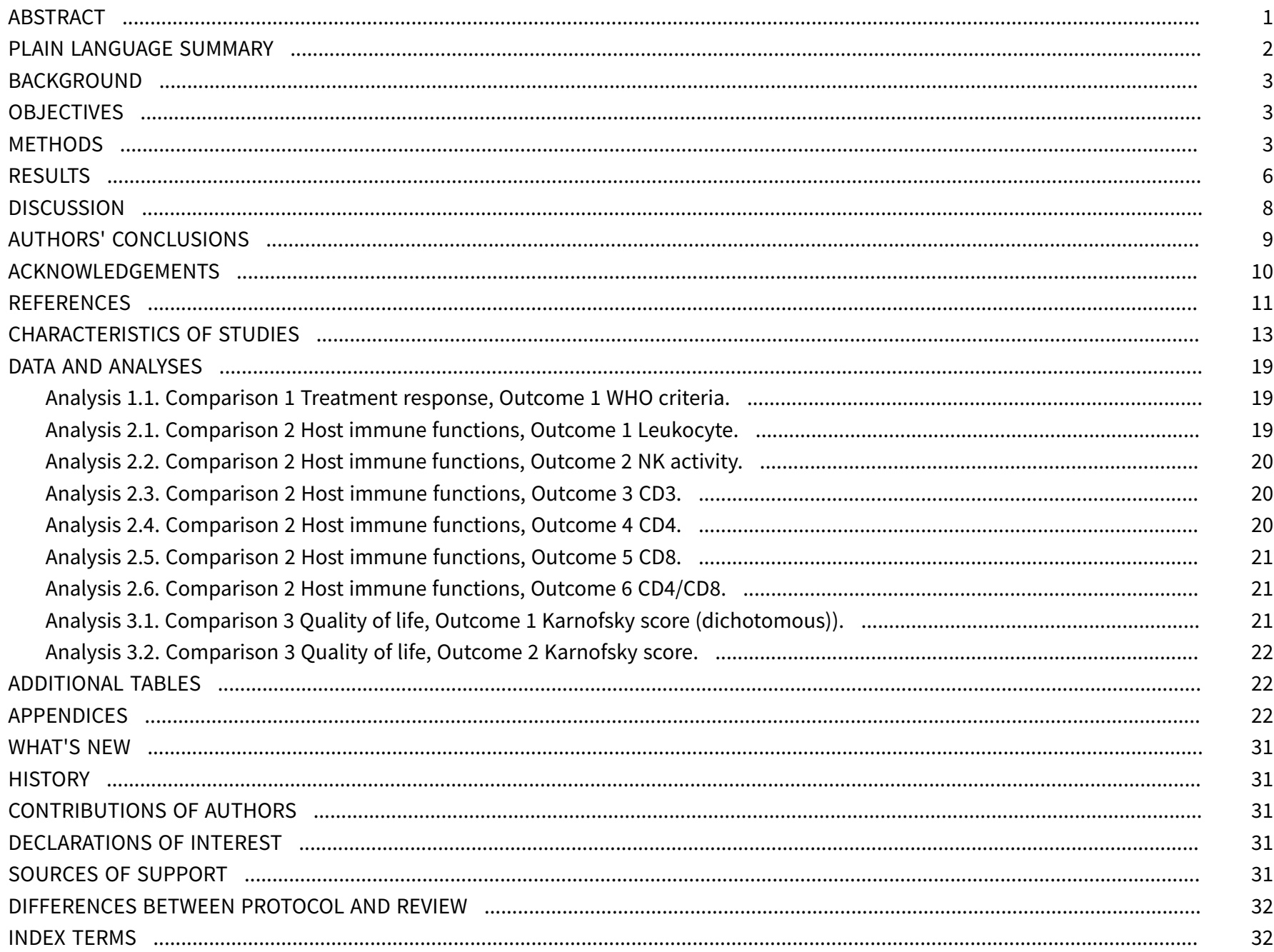


[Intervention Review]

\title{
Ganoderma lucidum (Reishi mushroom) for cancer treatment
}

\author{
Xingzhong Jin ${ }^{1}$, Julieta Ruiz Beguerie ${ }^{2}$, Daniel Man-yuen Sze 3 , Godfrey CF Chan 4
}

1Menzies Institute for Medical Research, University of Tasmania, Hobart, Australia. 2Dermatology Department, Austral University Hospital, Buenos Aires, Argentina. ${ }^{3}$ School of Health and Biomedical Sciences, RMIT University, Melbourne, Australia. ${ }^{4}$ Department of Pediatrics and Adolescent Medicine, The University of Hong Kong, Queen Mary Hospital, Hong Kong, China

Contact: Xingzhong Jin, Menzies Institute for Medical Research, University of Tasmania, 17 Liverpool Street, Hobart, Tasmania, 7000, Australia.jwjxz@hotmail.com.

Editorial group: Cochrane Gynaecological, Neuro-oncology and Orphan Cancer Group.

Publication status and date: Stable (no update expected for reasons given in 'What's new'), published in Issue 1, 2019.

Citation: Jin X, Ruiz Beguerie J, Sze DMY, Chan GCF. Ganoderma lucidum (Reishi mushroom) for cancer treatment. Cochrane Database of Systematic Reviews 2016, Issue 4. Art. No.: CD007731. DOI: 10.1002/14651858.CD007731.pub3.

Copyright ( 2019 The Cochrane Collaboration. Published by John Wiley \& Sons, Ltd.

\section{A B S T R A C T}

\section{Background}

Ganoderma lucidum is a natural medicine that is widely used and recommended by Asian physicians and naturopaths for its supporting effects on immune system. Laboratory research and a handful of preclinical trials have suggested that G. lucidum carries promising anticancer and immunomodulatory properties. The popularity of taking G. lucidum as an alternative medicine has been increasing in cancer patients. However, there is no systematic review that has been conducted to evaluate the actual benefits of $G$. lucidum in cancer treatment.

\section{Objectives}

To evaluate the clinical effects of $G$. lucidum on long-term survival, tumour response, host immune functions and quality of life in cancer patients, as well as adverse events associated with its use.

\section{Search methods}

We searched an extensive set of databases including the Cochrane Central Register of Controlled Trials (CENTRAL), MEDLINE, EMBASE, NIH, AMED, CBM, CNKI, CMCC and VIP Information/Chinese Scientific Journals Database was searched for randomised controlled trials (RCTs) in October 2011. Other strategies used were scanning the references of articles retrieved, handsearching of the International Journal of Medicinal Mushrooms and contact with herbal medicine experts and manufacturers of $G$. lucidum. For this update we updated the searches in February 2016.

\section{Selection criteria}

To be eligible for being included in this review, studies had to be RCTs comparing the efficacy of G. lucidum medications to active or placebo control in patients with cancer that had been diagnosed by pathology. All types and stages of cancer were eligible for inclusion. Trials were not restricted on the basis of language.

\section{Data collection and analysis}

Five RCTs met the inclusion criteria and were included in this review. Two independent review authors assessed the methodological quality of individual trials. Common primary outcomes were tumour response evaluated according to the World Health Organization (WHO) criteria, immune function parameters such as natural killer (NK)-cell activity and T-lymphocyte co-receptor subsets, and quality of life measured by the Karnofsky scale score. No trial had recorded long-term survival rates. Associated adverse events were reported in one study. A meta-analysis was performed to pool available data from the primary trials. Results were gauged using relative risks (RR) and standard mean differences (SMD) for dichotomous and continuous data respectively, with a 95\% confidence interval (CI). 


\section{Main results}

The methodological quality of primary studies was generally unsatisfying and the results were reported inadequately in many aspects. Additional information was not available from primary trialists. The meta-analysis results showed that patients who had been given $G$. lucidum alongside with chemo/radiotherapy were more likely to respond positively compared to chemo/radiotherapy alone (RR 1.50; $95 \%$ $\mathrm{Cl} 0.90$ to $2.51, \mathrm{P}=0.02)$. G. lucidum treatment alone did not demonstrate the same regression rate as that seen in combined therapy. The results for host immune function indicators suggested that $G$. lucidum simultaneously increases the percentage of CD3, CD4 and CD8 by $3.91 \%(95 \% \mathrm{Cl} 1.92 \%$ to $5.90 \%, \mathrm{P}<0.01)$, 3.05\% (95\% Cl $1.00 \%$ to $5.11 \%, \mathrm{P}<0.01$ ) and $2.02 \%(95 \% \mathrm{Cl} 0.21 \%$ to $3.84 \%, \mathrm{P}=0.03)$, respectively. In addition, leukocyte, NK-cell activity and CD4/CD8 ratio were marginally elevated. Four studies showed that patients in the G. lucidum group had relatively improved quality of life in comparison to controls. One study recorded minimal side effects, including nausea and insomnia. No significant haematological or hepatological toxicity was reported.

\section{Authors' conclusions}

Our review did not find sufficient evidence to justify the use of $G$. lucidum as a first-line treatment for cancer. It remains uncertain whether G. lucidum helps prolong long-term cancer survival. However, G. lucidum could be administered as an alternative adjunct to conventional treatment in consideration of its potential of enhancing tumour response and stimulating host immunity. G. lucidum was generally well tolerated by most participants with only a scattered number of minor adverse events. No major toxicity was observed across the studies. Although there were few reports of harmful effect of $G$. lucidum, the use of its extract should be judicious, especially after thorough consideration of cost-benefit and patient preference. Future studies should put emphasis on the improvement in methodological quality and further clinical research on the effect of $G$. lucidum on cancer long-term survival are needed. An update to this review will be performed every two years.

\section{PLAIN LANGUAGE SUMMARY}

\section{G. lucidum (Reishi mushroom) for cancer treatment}

There have been an increasing number of patients diagnosed with cancer each year. Certain malignancies have been a major cause of death in some populations. People who have been diagnosed with cancer want to do everything they can to combat the disease, manage its symptoms and cope with the side effects of radio/chemotherapy. Many turn to complementary and alternative medicine. G. lucidum extract is a medication that has been widely used by traditional Chinese medicine (TCM) practitioners for this regard. It is usually recommended as an immune system support supplement in cancer treatment. Latest laboratory research and preclinical trials of $G$. lucidum have shown promising results of its antitumour activity. However, clinical evidence of its efficacy is sparse and a systematic review is in need to provide collective information for health-care consumers.

Our review identified and subsequently included five relevant randomised controlled trials. A total of 373 subjects were analysed. A meta-analysis was performed to pool available data from individual trials. Our results found that patients with $G$. lucidum extract in their anticancer regimen were 1.27 times more likely to respond to chemotherapy or radiotherapy than those without. However, the data failed to demonstrate significant effect on tumour shrinkage when it was used alone. In addition, G. lucidum could stimulate host immune functions by considerably increasing CD3, CD4 and CD8 lymphocyte percentages. Nevertheless, natural killer (NK)-cell activity, which has been suggested to be an indicator of self-defence against tumour cell, was marginally elevated. Patients in the G. lucidum group were found to have a relatively better quality of life after treatment than those in the control group. A few cases of minor side effect associated with G. lucidum treatment including nausea and insomnia were reported.

There are limitations of the results from this systematic review. First, most included studies were small and there were concerns on the methodological quality of individual trials. Second, all participants in the individual trials were recruited from the Chinese population. Together, the robustness and applicability of the results were largely affected. 


\section{B A C K G R O U N D}

\section{Description of the condition}

In the year 2000 , malignant tumours were responsible for $12 \%$ of 56 million deaths worldwide from all causes. Around 5.3 million men and 4.7 million women developed a malignant tumour and together 6.2 million people died from their disease. According to the World Cancer Report by World Health Organization (WHO), cancer rates could further increase by $50 \%$ to 15 million new cases by 2020 (Steward 2003). Chemotherapy and radiotherapy are two routinely used adjuvant treatments for cancer patients in conventional medicine. A variety of adverse events are associated with these two treatments, such as myelosuppression, gastrointestinal discomfort and disorder, alopecia, fatigue, and even cardiac, respiratory and neural toxicity. These side effects have affected patients' long-term compliance to medication and have lowered their quality of life (QoL) (ONS 2005). As a result, numerous oncology studies have been initiated in order to find an alternative cancer medication over the past few decades. Ganoderma lucidum (G. lucidum) is one such substance that has been widely studied in traditional Chinese medicine (TCM) (Boh 2007).

\section{Description of the intervention}

G. lucidum [Latin] (also known as Reishi in Japan, Ling-zhi in China, Ling chih, and Ling chi mushroom in other countries) is a type of mushroom that grows on plum trees in Asia. It is popular among consumers in Japan and is widely used by Asian physicians and herbalists. This medicinal mushroom has been used in Asia for thousands of years to increase energy, stimulate the immune system, and promote health and longevity (Chang 1999). In the US, G. lucidum is included in the American Herbal Pharmacopoeia and is most often recommended for its immune-supporting effects (Upton 2000). In Poland and other countries outside Asia, G. lucidum is used as a daily food supplement that adapts itself to correct imbalances in the body (Jong 1992). Influenced by an increasing number of studies into G. lucidum, modern uses of G. lucidum include treatment for coronary heart disease, arteriosclerosis, hepatitis, arthritis, nephritis, bronchitis, hypertension, cancer and gastric ulcers (Boh 2007).

\section{How the intervention might work}

A systematic laboratory research elucidates that the anticancer and immunomodulatory properties of $G$. lucidum are largely contained in its diverse chemical constituents, whereas polysaccharides and triterpenes are two groups of prominent bioactive components (Chan 2005; Lee 1998).

The polysaccharides from $G$. lucidum are believed to trigger an indirect antitumour mechanism in which the host immune system is altered to target the tumour cells. The active polysaccharides are largely in the form of beta-glucans. It has been shown that beta-glucans have the ability to induce both innate and adaptive immune responses. The targeted immune cells include macrophages, neutrophils, monocytes, natural killer (NK) cells and dendritic cells. The branched chains of beta-glucans act on complement receptor type 3 (CR-3) triggering a series of molecular pathways such as NF-kB, mitogen-activated protein kinase (MAPK) and protein kinase $C(P K C)$, which in turn, activate the host immune response for immune cell proliferations (Hong 2004). Betaglucans also act on dectin-1 receptor and toll-like receptor 2 (TLR-2) (Brown 2006; Gantner 2003). The resultant actions are enhanced maturation of dendritic cells as well as increased opsonic and non-opsonic phagocytosis. Subsequently, cytokine production and splenic NK-cell cytotoxicity are increased (Chan 2007). All of these immune reinforcements are believed to have a contribution to the antitumour properties of G. lucidum (Sliva 2003). In addition, G. lucidum is the only known source of a particular group of triterpenes, also known as ganoderic acids, which have been found to have direct cancer cell cytotoxicity on a wide variety of cancer cell lines, such as murine Lewis lung carcinoma (LLC) and Meth-A, and many of them have been suggested to counter angiogenesis and metastasis (Min 2000).

\section{Why it is important to do this review}

Prompted by the promising anticancer potential established by laboratory studies, a few randomised controlled trials (RCTs) have been conducted to evaluate the clinical effectiveness of G. lucidum. However, the majority of clinical trials are conducted in Asia and published in Asian databases. Full-text publications are usually not available in English. To date, there is no systematic review that investigates the clinical usefulness of G. lucidum for cancer treatment. Since the prevalence of $G$. lucidum use in cancer patients has been increasing, the clinical usefulness of $G$. lucidum for cancer treatment needs to be scrutinised. Therefore, a systematic review based on existing RCTs is needed to provide up-to-date knowledge of $G$. lucidum in clinical practice, and to provide direction for future clinical trials in this field.

\section{O B JECTIVES}

To investigate the overall effectiveness of $G$. lucidum for the treatment of various cancers and its impact on long-term cancer survival rates.

To evaluate the immunomodulatory effects of $G$. lucidum and its impact on the QoL of cancer patients.

\section{METHODS}

\section{Criteria for considering studies for this review}

\section{Types of studies}

Eligible study designs were RCTs regardless of language and published status (published, pending, ongoing or unpublished). Cluster RCTs and randomised cross-over studies were also eligible. For randomised cross-over studies, only first phase data were included in the review. Other study designs were excluded.

\section{Types of participants}

Adult patients who were diagnosed with malignant tumour, regardless of origin, tumour stage, age and gender. The diagnosis must have been confirmed by biopsy.

\section{Types of interventions}

Intervention of interest was medication extracted from the plant G. lucidum, irrespective of preparations (raw plant, decoction, capsule, tablet, tincture, extract, injection) dosage and regimen. The medication could be derived from any part of G. lucidum (mycelium, stem, root, leave, spore).

As a comparison, eligible control included no intervention/ placebo, active conventional therapies (surgery, chemotherapy and radiotherapy) and other complementary and alternative 
medicines (CAM). All medications apart from active conventional therapies were regarded as CAM.

Eligible intervention combinations are listed in Table 1.

\section{Types of outcome measures}

Outcomes of interest were measured at the baseline of a trial, at the end of interventions and at the end of follow-up.

\section{Primary outcomes}

\section{Overall survival rate}

One-year, three-year and five-year survival resulting from all causes of death.

\section{Treatment response}

\subsection{WHO response criteria}

The WHO criteria for tumour response were developed and published in the early 1980s (WHO 1979, Miller 1981). It has been adopted as the standard method for evaluating tumour response to treatment. The evaluation is dependent on measurement of tumour size. Change of tumour size after treatment is estimated from bi-dimensional measurement (the product of the longest diameter and its longest perpendicular diameter for each tumour). There are four categories of response: complete response, partial response, stable disease and progressive disease.

\subsection{Response Evaluation Criteria in Solid Tumour (RECIST)}

RECIST is a validated evaluation criteria of cancer drugs for clinical trials, published in February 2000 by an international collaboration including the European Organization for Research and Treatment of Cancer (EORTC), National Cancer Institute ( $\mathrm{NCl}$ ) of the US and the National Cancer Institute of Canada Clinical Trials Group (Patrick 2000). RECIST is an approach based only on measurements in one dimension from new imaging techniques, such as computer tomography (CT) and magnetic resonance imaging (MRI). As with the WHO criteria, tumour responses for RECIST are divided into four categories: complete response, partial response, stable disease and progressive disease*.

* A Korean study (Park 2003) comparing the WHO criteria and the RECIST guidelines has concluded that two criteria guidelines are comparable in evaluating response in solid tumours.

\section{Secondary outcomes}

\section{Host immune functions}

Peripheral leukocyte count, phagocyte index ${ }^{\wedge}$ or phagocyte activity $^{\star}, \mathrm{T}$-cell and B-cell subset lymphocytes flow cytometry, NKcell activity, and tumour necrosis factor (TNF- $\alpha$ ) level.

$\wedge$ The average number of bacteria ingested by each phagocyte in an individual's blood after a mixture of the blood serum, bacteria and phagocytes has been incubated.

* The percentage of neutrophils that phagocytose.

\section{Quality of life (QoL)}

QoL was evaluated with any validated instrument, such as QOLS original Flanagan version (Flanagan 1982), Karnofsky score or original evaluation instrument used in the primary studies.

\section{Adverse events}

Incidence of all major and minor adverse events such as digestive upsets, skin rashes and hepatotoxicity.

\section{Search methods for identification of studies}

A literature search was performed to identify relevant RCTs from January 1980 to October 2011, regardless of published status (published, pending, ongoing or unpublished) and language of publication. We updated the searches in February 2016 (CENTRAL (Issue 1 2016)(Appendix 1), MEDLINE (Oct 2011 to Jan week 4 2016) (Appendix 2), EMBASE (Oct 2011 to 2016 week 5)(Appendix 3)).

\section{Electronic searches}

Following electronic databases were searched:

- the Cochrane Central Register of Controlled Trials (CENTRAL), on The Cochrane Library,

- MEDLINE,

- EMBASE,

- National Institute of Health (NIH),

- Allied and Complementary Medicine Database (AMED),

- Evidence-Based Medicine Review (EBMR), featuring Cochrane DSR, ACP Journal Club, DARE, CCTR, CLCMR and CLHTA,

- Chinese Biomedical Literature Database (CBM),

- China National Knowledge Infrastructure (CNKI),

- Chinese Medical Current Content (CMCC),

- VIP Information/Chinese Scientific Journals Database.

We also searched clinical trials registries in order to identify ongoing studies:

- International Standard Randomised Controlled Trial Number Register (ISRCTN),

- Clinical Trials.gov (clinicaltrials.gov),

- National Center for Complementary and Alternative Medicine (nccam.nih.gov/clinicaltrials/alltrials.htm),

- Chinese Clinical Trial Register (www.chictr.org),

- WHO International Clinical Trial Registration Platform Search Portal (www.who.int/trialsearch),

- Australian and New Zealand Clinical Trial Registry (www.anzctr.org.au/)

\section{Searching other resources}

We made an attempt to identify further published and unpublished trials by viewing the list of references from the individual studies that were retrieved from the electronic searches. We did a handsearch of thelnternational Journal of Medicinal Mushrooms. Experts in this field and manufacturers of $G$. lucidum were also contacted in order to locate further relevant articles.

\section{Data collection and analysis}

All identified studies were recorded in EndNote x2. Two review authors (XJ and JRB) were assigned to collect and extract data from identified studies. Details of individual studies were stored as paper documents with corresponding reference IDs in EndNote. 


\section{Selection of studies}

Two review authors ( $\mathrm{XJ}$ and JRB) independently engaged in the selection of studies and the assessment of eligibility for inclusion with any disagreement to be resolved by discussion. By screening titles, abstracts and keywords, information of identified studies was entered in an $\mathrm{I} / \mathrm{O}$ form (Appendix 4). Full texts were further assessed if the collected information suggested that a primary study was eligible for this review. When information contained in a study was not sufficient to make a judgement on its eligibility, attempt was made to contact the corresponding study authors and to obtain further details of the original study. A third review author (DS) helped translate studies in different languages into English before abstract and full text was examined.

\section{Inclusion Criteria}

1. RCTs, including cluster RCTs and randomised cross-over trials.

2. Human studies.

3. Participants with a confirmed diagnosis of cancer.

4. G. lucidum involved in at least one observational arm.

5. Investigation of at least one outcome as mentioned previously.

\section{Exclusion Criteria}

1. Any study designs other than RCTs.

2. Animal studies and in vitro studies.

3. Participants with no cancer diagnosis.

4. G. lucidum not involved as an intervention.

5. No outcome of interest observed.

\section{Data extraction and management}

We used a standard extraction form (Appendix 5) to collect data from each included trial and categorise into the following items:

1. General information: publishing status, language, authors, article title, journal title and year, volume, issue, page and funding source.

2. Participants: diagnostic criteria, total number and number in comparison groups, baseline characteristics, age, gender, inclusion criteria, exclusion criteria and study setting.

3. Intervention: type of preparation, dose, regimen, cointervention, withdrawals, loss to follow-up.

4. Outcome: primary outcomes, secondary outcomes and other outcomes at the end of treatment and/or the end of follow-up. The adverse events recorded will also be extracted.

5. Data analysis: study data in detail, statistical methods for data analysis.

\section{Assessment of risk of bias in included studies}

Corresponding authors of primary studies were contacted in order to obtain further methodological details of the original trials. Potential bias in trials was assessed using a 'Risk of bias' assessment form (Appendix 6). Individual primary study was appraised independently by two review authors (XJ and JRB) according to the criteria (Appendix 7) that are described in Cochrane Handbook for Systematic Reviews of Interventions (Higgins 2011). Based on the criteria, studies were summarised into three categories: low risk of bias, moderate risk of bias and high risk of bias. Discrepancy was settled by further discussion and a final judgement was made from the consensus between two review authors.

\section{Measures of treatment effect}

Treatment effect of interest was observed at the baseline of a trial, at the end of intervention of interest and at the end of follow-up.

\section{Unit of analysis issues}

We made efforts to obtain individual patient data (IPD) or any missing aggregated data by contacting corresponding authors of included studies. Where data were sufficient, a time-to-event analysis was conducted.

\section{Dealing with missing data}

We tried to obtain missing data from corresponding trialists. The impact of missing data was analysed via comparison between results including missing data and results excluding missing data.

\section{Assessment of heterogeneity}

Heterogeneity was assessed by inspecting the forest plots. Confidence intervals $(\mathrm{Cl})$ of studies overlapping with each other and the summary effect implied no or insignificant heterogeneity present. In addition, heterogeneity was tested by both $\mathrm{Chi}^{2}$ test and $\mathrm{I}^{2}$ test. A result of $\mathrm{Chi}^{2}>25 \%$ and $\mathrm{P}<0.10$ was defined as evidence of significant heterogeneity across studies. $1^{2}$ test was used to estimate the extent of variability across studies that was due to heterogeneity. A result higher than $30 \%$ would represent moderate heterogeneity and higher than $50 \%$ would represent substantial heterogeneity (Higgins 2003). Possible sources of heterogeneity were explored by subsequent subgroup analyses and sensitivity analyses.

\section{Assessment of reporting biases}

Funnel plots of treatment effect against its standard error were used to explore publication bias and 'small-study effects', depending on the number of primary studies included in this systematic review. Asymmetry in funnel plots implied possible small-study effects. A modified 'Egger' regression test was conducted to detect such asymmetry (Harbord 2005). P $<0.10$ was deemed to have considerable small-study effects.

\section{Data synthesis}

Where appropriate, differences in outcomes comparing treatment and control groups were combined across studies using generic inverse-variance methods for meta-analysis. All data analyses were performed on RevMan 5. Summary estimates were presented in forest plots.

Fixed-effect model was used. If there was presence of heterogeneity among studies, we compared results between fixed-effect model and random-effects model.

Survival rates, treatment response and adverse events were considered to be dichotomous data. For treatment response regardless of which criteria were used, responders were defined as patients who achieved complete response or partial response according to the criteria, while other patients who had a result of stable disease or progressive disease were considered as nonresponders (Chinn 2000). 
Host immune function indicators and scores of QoL were treated as continuous data when data obtained was sufficient and appropriate. In cases where data for the same outcome were presented as dichotomous data in some studies and as continuous data in other studies, we contacted the corresponding authors for any missing data. When the authors were not able to be contacted, we converted the dichotomous data into continuous data by using the method introduced in Section 9.4.6 of the Cochrane Handbook for Systematic Review of Interventions (Higgins 2011).

Relative risk (RR) and its $95 \% \mathrm{Cl}$ were used for estimating the overall effects of dichotomous data. Weighted mean difference (WMD) and its $95 \% \mathrm{Cl}$ were used for continuous data if an outcome had been measured using the same scale, or else standard mean difference (SMD) would be used instead.

\section{Subgroup analysis and investigation of heterogeneity}

Subgroup analyses were planned to carry out in terms of the following aspects:

1. Different dosage regimens of G. lucidum treatment.

2. Different origins of tumour.

3. Different stages of cancer.

4. Whether or not combined with active conventional treatments or (and) other complementary medications in addition to $G$. lucidum treatment.

5. Different parts of G. lucidum used in the trials (e.g. spore versus mycelium).

\section{Sensitivity analysis}

Sensitivity analyses were prespecified to explore the influence of the following factors:

1. Repeating data analysis excluding unpublished studies (if there is any).

2. Compare analysis including missing data against analysis excluding missing data.

3. Compare analysis excluding studies with high risk of bias against the original meta-analysis.

\section{RES U LTS}

\section{Description of studies}

\section{Results of the search}

Our search yielded a total of 257 studies from the electronic databases. After screening off repetitive and clearly irrelevant studies, 35 studies remained eligible for abstract and full-text assessment. Six reviews, 10 non-randomised trials, two case reports and one irrelevant trial were further excluded. Two RCTs (Huang 2001; Wang 2005) were excluded because no outcome of interest was observed in the study. Seven RCTs (Jing 2007; Liang 2002; Ma 2003; Mo 1999; Pan 2007; Zhang 1999; Zhuang 2009) were further excluded due to the use of herbal mixture instead of pure G. lucidum and one study (Song 2006) was also excluded because another species $G$. capense in the family was used. Another RCT (Kuang 2007) was excluded after scrutiny over the text because it appeared to have apparent reporting errors. It reported that 56 patients were randomly allocated into two equal groups, however the total number of patients was 39 in the experiment and 17 in the control when tumour responses were reported. The remaining five
RCTs were included in this systematic review. One ongoing study (Matthew 2010) was identified on the clinical trial registers. The status of the study was complete yet unpublished. Contact with the corresponding trialist to retrieve trial data was attempted; however, the trialist refused to disclose any data from the trial. From the 2016 updated searches we retrieved an additional 74 references. However, no additional studies were identified for inclusion.

\section{Included studies}

Five RCTs were included in this systematic review. Four of them were retrieved from $C$ hinese databases and full-texts were reported in Chinese. Only one RCT (Gao 2003b) was reported in English and was able to be identified on EMBASE or MEDLINE. All trials evaluated the effectiveness of commercial preparations of $G$. lucidum. Except for one study (He 1997) in which 160 patients were enrolled, most individual studies were small trials with a sample size less than 100. Three studies (Gao 2003b; Yan 1998; Zhang 2000) evaluated the effects of $G$. lucidum in advanced lung cancer, one (Leng 2003) in post-surgical rectal cancer and one (He 1997) in various cancers with the same TCM symptomatology.

\section{Excluded studies}

Excluded studies and reasons for exclusion were listed in Characteristics of excluded studies.

\section{Risk of bias in included studies}

\section{Allocation}

All included studies made a statement in their reports that the allocation of study subjects was randomised, but none of them provided explicit description. In one study (Zhang 2000), the subjects were allocated according to enrolment order and it was unclear whether efforts had been made to achieve allocation concealment. Review authors therefore judged that there might be considerable selection bias in this study. One study (He 1997) included very limited information with regard to random sequence generation and a very high risk of selection bias was suggested by the marked difference in size between two arms, 100 in observation versus 60 in control.

\section{Blinding}

In two studies (Gao 2003b; Zhang 2000), a placebo of same appearance and taste had been specifically invented and used in order to blind both patients and doctors to study design. Other included studies were open trials where blinding had not been done or attempted in an inappropriate manner. Two studies (He 1997; Yan 1998), in which outcomes potentially influenced by subjective judgement of patients or clinicians were measured, such as QoL, were particularly subject to a high risk of detection bias. Whereas other studies in which objective testing (e.g. blood count, NK-cell activity and T-lymphocyte subsets) was the only measure, the results of these studies were unlikely to be affected by the absence of blinding.

\section{Incomplete outcome data}

In the He 1997 study, 160 cancer patients were recruited into the trial but only 10 patients were included in the haematological analysis. No explanation was found in the text for the incomplete outcome data. In the Gao 2003b study, eight subjects (five in the treatment group and three in the control group) were lost to followup and excluded from the final data analysis. 


\section{Selective reporting}

We tried to contact the authors of all included studies in order to obtain trial protocols and IPD. Unfortunately none of the authors could be reached to provide the information. Reporting bias could therefore only be assessed on the basis of available published study reports. In the He 1997 study, investigations in lymphocyte, platelet and immunoglobulins were proposed in the Methods section but data were omitted in the Results section.

\section{Other potential sources of bias}

In one study (He 1997), there was a significant imbalance between the observation group and the control group in terms of number of subjects. We could not obtain further details from the study author, and there was no explanation for this in the report. This raised review authors' concerns on pseudo-randomisation or other potential bias.

\section{Effects of interventions}

\section{Survival rate}

No included study had recorded survival data; hence data analysis in this regard was unavailable in this review.

\section{Treatment response}

Three included studies (Gao 2003b; Yan 1998; Zhang 2000) had measured the short-term response of lung cancer to G. lucidum treatment according to the WHO criteria (1979). As prespecified in the protocol of this review, complete response or partial response were categorised as positive responses while other responses, including stable disease and progressive disease, were defined as a negative response. The data extracted from the primary studies were pooled and presented in a forest plot (Analysis 1.1). In the Gao 2003b study, no cancer patients in either G. lucidum or placebo arm yielded a positive outcome, therefore the study was not able to contribute to the analysis. The RR pooled from the other two studies suggested that tumour shrinkage was more likely when patients were on G. lucidum, however the result was statistically insignificant (RR $1.50 ; 95 \% \mathrm{Cl} 0.90$ to $2.51 ; \mathrm{P}=0.12$ ).

This result should be taken with caution because G. lucidum may not have a significant antitumour effect when it is used as a solitary treatment. This was particularly demonstrated by the equally zero case of positive response in both arms in the Gao 2003b study, where neither $G$. lucidum nor placebo was used in company with any conventional therapy. Although patients in the G. lucidum group had a relatively lower PD rate $(51.4 \%)$ after treatment, compared to that of those who received placebo (67.7\%), the author speculated that tumours were more likely to respond to cancer treatment when G. lucidum was incorporated into a cancer treatment regimen with chemo/radiotherapy. In contrast, in the Yan 1998 study and the Zhang 2000 study patients who received $G$. lucidum treatment in combination with conventional chemotherapy generally responded more positively than those in the standard treatment group.

\section{Host immune functions}

For studies in which only the means of values at the baseline and endpoint were reported, the mean difference (MD) and standard deviation comparing before and after treatment were computed according to the following formula:
$M D(C)=M D(A)-M D(B)$

$\mathrm{SD}(\mathrm{C})=\mathrm{SQRT}\left(\mathrm{SD}(\mathrm{B}) 2+\mathrm{SD}(\mathrm{A}) 2-2^{\star} R^{\star} \mathrm{SD}(\mathrm{B})^{\star} \mathrm{SD}(\mathrm{A})\right)$

$\mathrm{MD}$, mean difference; SD, standard deviation; SQRT, square root; $R$ was defined as a value of 0.5 in this review.

$A$, endpoint measures; $B$, baseline measures; $C$, value change in measures.

\subsection{Leukocyte}

Change in leukocyte count $\left(\times 10^{9} / \mathrm{L}\right)$ after treatment was measured in only one study (Yan 1998), which showed that G. lucidum treatment had the property of attenuating leukocytic depletion resulted from the cytotoxicity of chemotherapy (MD 1.52; $95 \% \mathrm{Cl}$ 0.59 to $2.45 ; P=0.12$ ) (Analysis 2.1).

\subsection{NK-cell activity}

Two studies (Gao 2003b; Zhang 2000) had measured the effect of $G$. lucidum on boosting NK-cell activity. The results from these two studies showed completely opposite directions in effect. While the results of the Gao 2003b study favoured the use of G. lucidum and showed an increase in NK-cell activity after its use, the Zhang 2000 study did not support the same and even indicated a slightly negative impact. As a result, our meta-analysis yielded a statistically insignificant overall value (SMD $0.45 ; 95 \% \mathrm{Cl}-1.60$ to 2.50; $\mathrm{P}=0.67)$ with a substantial degree of heterogeneity $\left(\mathrm{Chi}^{2}=\right.$ 17.78; $\mathrm{P}<0.01 ; \mathrm{I}^{2}=94 \%$ ) (Analysis 2.2).

\subsection{T-cell subsets}

All included studies but one (He 1997) had measured complete Tlymphocyte subset counts. From the pooled results, it showed a general improvement of immunological status in cancer patients who had taken G. lucidum treatment (Analysis 2.3; Analysis 2.4; Analysis 2.5; Analysis 2.6). Overall, the value of CD3 was increased by an average of $3.91 \%(95 \% \mathrm{Cl} 1.92 \%$ to $5.90 \%$; $\mathrm{P}<0.01)$, CD4 by $3.05 \%(95 \% \mathrm{Cl} 1.00 \%$ to $5.11 \%$; $\mathrm{P}<0.01)$, as well as CD8 by $2.02 \%(95 \% \mathrm{Cl} 0.21 \%$ to $3.84 \% ; \mathrm{P}=0.03)$. There was only a marginal improvement in terms of the CD4/CD8 ratio with an overall increase of $0.12(95 \% \mathrm{Cl} 0.01$ to $0.23 ; \mathrm{P}=0.03)$. Interestingly, all immune parameters in the Zhang 2000 study were decreased in the G. lucidum group, which were in opposition to results of the other three studies. A number of factors might have contributed to the conflict of results, including small sample size, poor methodological quality (especially due to high risk in randomisation failure) and statistical randomness. The study also contributed to the significantly high $1^{2}$ value observed in the analysis. Exclusion of the study from the analysis could resolve the high heterogeneity test values, however there was no strong rationale for such exclusion, particularly in consideration of limited number of studies in our analysis. Again, we believe that small sample size and poor methodology are the major contributors to the significant heterogeneity among the studies.

\section{Quality of life (Karnofsky score)}

The impact on QoL by the incorporation of G. lucidum treatment was evaluated in four studies by comparing the Karnofsky scores (Gao 2003b; He 1997; Yan 1998; Zhang 2000). One study (Zhang 2000) reported the mean changes in score values after treatment and the other three (Gao 2003b; He 1997; Yan 1998) presented the results in a format of dichotomous data. Therefore, we combined 
the data separately according to the type of data (Analysis 3.1; Analysis 3.2). Qualitatively, the use of G. lucidum in cancer patients had a positive impact on QoL, as more subjects had achieved an increase in Karnofsky score after intervention in the G. lucidum group than the control group (RR 2.51; $95 \% \mathrm{Cl} 1.86$ to 3.40; $\mathrm{P}<$ 0.01). Quantitatively, the results from the Zhang 2000 also favoured the use of G. lucidum. Average Karnofsky score was decreased in both groups after intervention, but the value was less affected in the patients receiving $G$. lucidum treatment compared to placebo, resulting in a relatively positive MD favouring $G$. lucidum treatment despite the difference being statistically insignificant (MD 12.70; $95 \% \mathrm{Cl}-4.72$ to $30.12 ; \mathrm{P}=0.15$ ).

\section{Adverse events}

One study (Gao 2003b) reported three episodes of toxicity in patients receiving $G$. lucidum treatment. Two experienced nausea and one had insomnia. No patients developed hepatitis or abnormal liver function tests. No haematological or biochemical toxicity was recorded in all included studies.

\section{Subgroup analyses and sensitivity analyses}

Because of limited number of trials and insufficient IPD from primary studies, prespecified subgroup analyses could not be carried out. A sensitivity analysis comparing high-risk studies and low-risk studies was performed when investigating lymphocyte subset results. As stated previously, the inadequate subject randomising method and the lack of allocation concealment in the Zhang 2000 study might have largely contributed to its discrepancy in results from the other three included studies (Gao 2003b; Leng 2003; Yan 1998).

\section{DISCUSSION}

The objective of this systematic review was to evaluate the efficacy and safety of $G$. lucidum in cancer treatment using evidence from RCTs. The intention of meta-analysis is to pool available data from individual trials to produce an overall summary measure of effects, including long-term survival rates, tumour response, immune response and QoL.

\section{Summary of main results}

A total of five RCTs with 373 subjects were included in this review and subsequent meta-analysis. Our results suggested that incorporation of $G$. lucidum treatment could potentially improve tumour response of lung cancer to conventional therapy. In other words, G. lucidum could have a synergetic potential with chemo/ radiotherapy to obtain an increase in CR/PR rates in patients with lung cancer. However, there is no current evidence that has shown that the increased tumour response would translate into improved long-term survivals. In addition, our review does not support the use of $G$. lucidum as a stand-alone treatment for cancer treatment as its antitumour effect was found to be almost negligible when it was used alone and was evaluated by the WHO criteria of tumour response (WHO 1979).

Our findings also showed that $G$. lucidum could be capable of enhancing immunity in cancer patients by stimulating Tlymphocyte proliferation, suggesting that $G$. lucidum could be a promising adjunct to counter the unwanted but common immunosuppressive effect of many chemotherapeutic drugs. Overall, CD3, CD4 and CD8 percentages were improved or less depleted by $3.91 \%, 3.05 \%$ and $2.02 \%$, respectively, after $G$. lucidum treatment for one to three months, compared to standard treatments. However, NK-cell activity, which had been postulated by a number of studies in this field to be an important mechanism of G. lucidum's antitumour effect (Gao 2003a; Gao 2005b; Brittenden 1996; Zheng 2011), was found to be little changed in our review and the results were inconclusive.

QoL was relatively improved in cancer patients with G. lucidum treatment than without. Overall Karnofsky score was relatively increased qualitatively and quantitatively in patients after $G$. lucidum treatment. Only one study recorded minor adverse events associated with the use of G. lucidum. Side effects included minor GI tract upset (nausea) and sleep disturbance (insomnia). No major haematological or hepatological toxicity was observed.

\section{Overall completeness and applicability of evidence}

Antitumour effect and immunity enhancement are the two major properties of $G$. lucidum as suggested by preclinical studies. Our review focused on the assessment of survival rate, tumour response and immune function indicators, while QoL and adverse events were also investigated. However, up to the date of this review, no RCT has investigated whether $G$. lucidum treatment produces benefits on survivals in the long term. Among all included studies, the RCT conducted by Gao 2003b was so far the most comprehensive trial in which all the outcomes of interest except survival rates had been investigated. We were able to assess the short-term tumour response evaluated by the WHO criteria (WHO 1979). The results favoured the incorporation of G. lucidum into conventional treatment but more studies are needed to confirm this. The effects of $G$. lucidum on leukocyte and NK-cell activity were inconclusive and controversial in our review due to the insufficient number of studies reporting these outcomes. Given the available data at the time of this review, we were able to conclude a positive effect of $G$. lucidum on T lymphocyte proliferation, as well as on QoL of cancer patients.

The improved tumour response is only applicable to lung cancer patients as it is the only type of cancer that was investigated in terms of short-term treatment response. Whether this effect would occur in different subtypes of lung cancer is unknown due to insufficient IPD. In addition, the positive outcomes of treatment response are only applicable when lung cancer patients are given G. lucidum regimen along with traditional standard treatment. Tlymphocyte proliferation was generally increased by G. lucidum regardless of the type of cancer. Other possible co-founding factors, for example age, could not be compared because of the scarcity of IPD. Coincidentally, all five primary studies recruited research subjects from the Chinese population. Thus, it is possible that there could be some variations in effects when the results in this review are applied to other demographical groups.

\section{Quality of the evidence}

Overall, the methodological quality of the included studies was unsatisfactory. Most trials failed to detail the process of random sequence generation and the strategy of allocation concealment clearly in the report. The randomisation process is critical to prevent allocation bias, but it is difficult to evaluate when the details of the process is not included in the report and we were unable to contact the corresponding authors. Three out of five included studies were open trials, of which two were subject to high 
risk of bias when a subjective score of QoL was measured. Among all the studies, Gao 2003b was of the highest methodological quality while He 1997 was on the other end of the spectrum. Paradoxically, the He 1997 study was the biggest clinical trial and the only included study that had a sample size over 100 subjects. Unfortunately, the obvious imbalance of subject numbers between groups, along with its poor study design and reporting standards, had compromised its robustness of evidence. All studies clearly reported loss to followup and incomplete data.

The small sample size and unclear risk of random sequence generation were the two greatest disadvantages in regard to the quality of the evidence in this review. The Zhang 2000 study was the smallest study and had a high risk in random sequence generation due to the use of alternate assignment approach and the absence of allocation concealing strategy. The impact of these two factors were demonstrated when T-lymphocyte subgroup data were pooled. The study yielded an opposite direction of effect against three other studies and largely contributed to the significant heterogeneity among studies.

\section{Potential biases in the review process}

We have performed a thorough literature search for both published and unpublished studies from an extensive set of databases. The literature search has not been restrained by language limitations. All available trials have been included in the systematic review. We have investigated all the important end points including benefits and harms instead of solely looking at a particular measurement. We have been able to provide some clarification on the clinical usefulness of $G$. lucidum in cancer treatment.

However, our review also has limitations. First, data retrieved from the primary studies were rather sparse. We were not able to perform a meta-analysis on all the important outcomes prespecified in the protocol, for example, long-term survival rates. Second, there was a great divergence in the methodological quality of included studies, with some being of low risk of bias and the other having high risk of bias. Inclusion of the high-risk studies into our meta-analysis could have led to biased or misleading results. The sensitivity analyses performed in our review have also shown methodological quality could have been a key factor that had influenced the opposing results across studies. Third, despite our effort to be free of regional limitations, the studies identified and included in this review all evaluate effects on subjects from the Chinese population. Such unintentional bias may have resulted in restriction and uncertainty when it comes to application of the results from our review.

Finally, we have not been able to perform all the subgroup analyses that were predefined in the protocol due to small number of trials in the subgroups. Thus we have not been able to differentiate the effectiveness of $G$. lucidum in the treatment for different types and stages of cancer, making the results of our review relatively indefinite and somewhat over generalised.

\section{Agreements and disagreements with other studies or reviews}

This review is the first systematic review and meta-analysis to investigate the effectiveness of G. lucidum for cancer treatment. Despite the fact that preclinical studies have established promising antitumour properties of $G$. lucidum extract, the results of this metaanalysis do not conclusively confirm the findings from previous studies. The use of $G$. lucidum alone does not demonstrate significant clinical benefits in achieving a better tumour response. Our review shows that $G$. lucidum can relatively improve immune functions that are usually depressed by chemo/radiotherapy, which is consistent with previous clinical trials and reviews. Past reviews speculated that enhanced cytokine production and NK-cell activity are factors that contribute to the anticancer property of $G$. lucidum, however, the results of this review show that the effect of G. lucidum on NK-cell activity is negligible.

\section{AUTHORS' CONCLUSIONS}

\section{Implications for practice}

The five studies included in this review do not provide clear and unbiased evidence to support the first-line use of G. lucidum in treatment for cancer patients. There is lack of evidence to support the point that the use of $G$. lucidum in advanced cancer therapy improves long-term survival. We do not recommend administration of $G$. lucidum preparations as a single treatment to patients with advanced cancer. However, the results of this review suggest that a better response may be expected when a G. lucidum preparation is incorporated as an adjuvant in conventional chemo/radiotherapy regimens. Regimens that incorporate G. lucidum are 1.25 times more likely to yield a better tumour response than those do not. Also, G. lucidum preparations can be administered in order to counter the immunosuppressive effect of chemo/radiotherapy, especially in terms of T-lymphocyte depletion. Similar to other natural remedies, $G$. lucidum is well-tolerated by cancer patients leading to better QoL and a relatively improved Karnofsky score. No severe toxicity has been observed according to current evidence. In short, current evidence does not support routine use of $G$. lucidum in all cancer patients. The decision of whether to use a G. lucidum preparation in an anticancer regimen should be made after careful consideration of cost-benefit potential and patients' preferences. Given the results of this review and from a cultural perspective, it could beneficial to add G. lucidum to the regimen for patients who have a Chinese background.

\section{Implications for research}

Currently, the evidence of using G. lucidum for cancer is sparse and the methodological quality of the trials is poor. As a result, we have only been able to draw a few definite conclusions from the evidence. The lack of standardisation in several aspects among included trials, for example uniformed preparation and administration of $G$. lucidum, and failure to include key information in the published reports, have jeopardised the reliability and validity of the original trials. Future studies should make efforts to address the following issues of trial design and reporting:

1. Full details of the enrolment sequence generation and subsequent strategy for allocation concealment should be included in the published reports.

2. True randomisation (e.g. shuffling envelopes or computer random numbers) should be adopted instead of simple or pseudo-randomisation (e.g. hospital record number).

3. Clinicians, patients and assessors should be blinded (e.g. use of a placebo) to prevent conscious or subconscious bias that may subsequently invalidate the results.

4. An intention-to-treat (ITT) analysis should be applied to all future trials to avoid bias and false-positive results. Complete information and reasons for participants who are enrolled and 
allocated to treatment groups but drop out of the assigned groups, should be provided.

5. Standardisation of methods of data presentation and data analysis. Reporting of results should be improved according to standard guidelines (CONSORT 2010).

In this review, we have been able to clarify the beneficial effect from $G$. lucidum on tumour response, immune functions and QoL assessment. The findings are relatively general and vague. Future clinical trials should explore the clinical potential of G. lucidum in the following aspects:

1. The effect of $G$. lucidum on one particular type of cancer should be further explored so as to differentiate the effectiveness of $G$. lucidum across different types of malignancy.

2. The staging of cancer should be standardised and well documented in future trials so that the responsiveness of different stages of cancer to G. lucidum treatment can be compared in future reviews.
3. Long-term survival is an important end-point assessment and should be investigated in any clinical trials of patients with cancer. It is of utmost importance to decide the clinical usefulness of an agent in cancer treatment.

4. Data from demographic groups other than the Chinese population are needed to explore the clinical applicability of $G$. lucidum in the future.

\section{ACKNOWLEDG MENTS}

We thank Markus Horneber and Chris Williams for editorial advice; Claudia Lodaza-Can, Nerida Klupp and Kathie Godfrey for their peer review comments and Gail Quinn for coordinating title registration and review submission.

This project was supported by the National Institute for Health Research, via Cochrane Infrastructure funding to the Cochrane Gynaecological, Neuro-oncology and Orphan Cancer Group. The views and opinions expressed therein are those of the authors and do not necessarily reflect those of the Systematic Reviews Programme, NIHR, NHS or the Department of Health. 


\section{R E F E R E N C E S}

\section{References to studies included in this review}

\section{Gao 2003b \{published data only\}}

Gao Y, Dai X, Chen G, Ye J, Zhou S. A randomized, placebocontrolled, multicenter study of Ganoderma lucidum (w.curt.:fr.) Lloyd (aphyllophoromycetideae) polysaccharides (ganopoly) in patients with advanced lung cancer. International Journal of Medicinal Mushrooms 2003;5(4):369-81.

\section{He 1997 \{published data only\}}

* He W, Yi J. Study of clinical efficacy of Lingzhi spore capsule on tumour patients with chemotherapy/radiotherapy. Clinical Journal of Traditional Chinese Medicine 1997;9(6):292-3.

\section{Leng 2003 \{published data only\}}

* Leng K, Lu M. Investigation of ZhengQing Lingzhi liquid as adjuvant treatment on patients with colon cancer. Journal of Guiyang Medical College 2003;28(5):1.

\section{Yan 1998 \{published data only\}}

* Yan B, Wei Y, Li Y. Effect of Laojunxian Lingzhi oral liquid combined with chemotherapy on non-parvicellular lung cancer at stage II and III. Traditional Chinese Drug Research \& Clinical Pharmacology 1998;9(2):78-80.

Zhang 2000 \{published data only\}

* Zhang X, Jia Y, Li Q, Niu S, Zhu S, Shen C. Clinical curative effect investigation of Lingzhi tablet on lung cancer. Chinese Traditional Patent Medicine 2000;22(7):486-8.

\section{References to studies excluded from this review}

Chen 2006 \{published data only\}

* Chen X, Hu ZP, Yang XX, Huang M, Gao Y, Tang W, et al. Monitoring of immune responses to a herbal immunomodulator in patients with advanced colorectal cancer. International Immunopharmacology 2006;6(3):499-508.

Gao 2003a \{published data only\}

* Gao Y, Zhou S, Jiang W, Huang M, Dai X. Effects of ganopoly (a Ganoderma lucidum polysaccharide extract) on the immune functions in advanced-stage cancer patients. Immunological Investigations 2003;32(3):201-15.

\section{Gao 2004 \{published data only\}}

Gao Y, Tank W, Gao H, Lan J, Zhou S. Chemopreventive, and tumoricidal properties of Ling Zhi mushroom Ganoderma lucidum (w. Curt.:fr.) Lloyd (aphyllophoromycetideae). Part i. Preclinical and clinical studies. International Journal of Medicinal Mushrooms 2004;6(2):95-106.

\section{Gao 2005a \{published data only\}}

* Gao Y, Tang W, Dai X, Gao H, Chen G, Ye J, et al. Effects of water-soluble Ganoderma lucidum polysaccharides on the immune functions of patients with advanced lung cancer. Journal of Medicinal Food 2005;8(2):159-68.
Gao 2005b \{published data only\}

Gao Y, Tang W, Dai X, Gao H, Chen G, Ye J, et al. Immune responses to water-soluble Ling Zhi mushroom Ganoderma lucidum (W.Curt.:Fr.) P. Karst. Polysaccharides in patients with advanced colorectal cancer. International Journal of Medicinal Mushrooms 2005;7(4):525-37.

Gill 2008 \{published data only\}

Gill SK. Rieder MJ. Toxicity of a traditional Chinese medicine, Ganoderma lucidum, in children with cancer. Canadian Journal of Clinical Pharmacology 2008;15(2):e275-85.

Huang 2001 \{published data only\}

* Huang J, Zhong X, Li G. Therapeutic effect of mixture Lingzhi with CD3/NK cell on lung cancer. Modern Journal of Integrated Traditional Chinese and Western Medicine 2001;10(8):704-5.

Jia 2005 \{published data only\}

Jia HQ, Wu SH, Wu J. Clinical analysis of Lingzhi spore in prostate cancer treatment. Andrology 2005;9(4):18-9.

\section{Jing 2007 \{published data only\}}

* Jing J, Zhu X, Li B, Jie Y. Clinical comparative investigation of Bailong capsule and liquid in combination with chemotherapy for digestive tumor. Shanxi Medical Journal 2007;36(7):631-3.

Kuang 2007 \{published data only\}

* Kuang J, Wang J, Kuang J. Investigation of effectiveness of Sporoderm-Broken Lingzhi spore powder in conjunction with chemotherapy on malignant tumour. Shangdong Medical Journal 2007;47(21):59-60.

Li Y. Clinical investigation of immunological indications of hematological malignancy. Journal of Guangxi Medical College 2000;17(2):54-6.

Li 2000 \{published data only\}

Li G, Cheng H. A Clinical Study on Immunity Regulation Function of Shenqi Lingzhi Regimen on Tumour Patients. Forum On Traditional Chinese Medicine 2000;15(6):29-30.

Liang 2002 \{published data only\}

* Liang J, Li Y, Wang S. Effect of radiotherapy combined with a medicine Lingzhi-912 on treatment of esophageal cancer. Journal of The Forth Military Medical University 2002;23(3):278-80.

Ma 2003 \{published data only\}

Ma MQ. Immunomodulatory effects of Chen-Ling antitumour capsule on tumour patients. China's Naturopathy 2003;11(8):38-9.

Mahajna 2009 \{published data only\}

Mahajna J, Dotan N, Zaidman BZ, Petrova RD, Wasser SP. Pharmacological values of medicinal mushrooms for prostate cancer therapy: the case of Ganoderma lucidum. Nutrition \& Cancer 61;1:16-26. 
Mo 1999 \{published data only\}

* Mo H, Hong M, Zhang J. Effect of Wuse - Lingzhi - Jiaonang on reducing side-effects of radiotherapy and improving immune function in patients with nasopharyngeal cancer. Chinese Journal of Clinical Oncology 1999;26(3):216-8.

Niu 2002 \{published data only\}

Niu Z. Observation of 30 cases of advanced malignant tumours treated by Zhonghua Lingzhi Bao. Shanxi Oncology Medicine 2002;10(3):225-6.

\section{Pan 2007 \{published data only\}}

* Pan S, Sun W. The clinical efficacy study of ginseng and Ganoderma lucidum essence - reinforcing pills combine with chemotherapy for malignant tumours. Liaoning Journal of Traditional Chinese Medicine 2007;34(10):1411-3.

\section{Qi 1999 \{published data only\}}

Qi Y, Li X, Yan M, Liu A, Jiao Z, Liu H. Clinical investigation of Lingzhi spore powder in adjuvant treatment of digestive tumours. Chinese Journal of Integrated Traditional and Western Medicine 1999;19(9):554-5.

\section{Simerpal 2008 \{published data only\}}

* Gill SK. Rieder MJ. Toxicity of a traditional Chinese medicine, Ganoderma lucidum, in children with cancer. Canadian Journal of Clinical Pharmacology 2008;15(2):e275-85.

\section{Sliva 2003 \{published data only\}}

Sliva D. Ganoderma lucidum (Reishi) in cancer treatment. Integrative Cancer Therapies 2003;2(4):358-64.

Sliva 2006 \{published data only\}

Sliva D. Ganoderma lucidum in cancer research. Leukemia Research 2006;30(7):767-8.

\section{Song 2006 \{published data only\}}

* Song Z, Cong Z, Wei J. Clinical investigation of Bozhi glycopeptide injection combined with chemotherapy for advanced-stage malignancy. Journal of Nantong University (Medical Sciences) 2006;26(6):474-5.

Wang 1999 \{published data only\}

Wang $\mathrm{HJ}$, Zhang $\mathrm{H}$. Clinical research of Lingzhi in cancer treatment. Journal of Dalian Medical College 1999;21(1):29-31.

\section{Wang 2005 \{published data only\}}

* Wang JW. Observation on the side effect of "Gloosy Ganoderma Spores Powder" combined with Qining injection in the treatment of 28 patients with malignant tumor and nursing care. Journal of Qilu Nursing 2005;13(17):1-2.

\section{Xu 2000 \{published data only\}}

Xu Z, Zhou R, Wei H. Clinical observation of Tian-an Lingzhi capsule in 120 patients with malignant tumours. The Journal of Pharmaceutical Practice 2000;18(4):197-9.

Yuen 2005 \{published data only\}

Yuen JW, Gohel MD. Anticancer effects of Ganoderma lucidum: a review of scientific evidence. Nutrition \& Cancer 2005;53(1):11-7.
Zhang 1999 \{published data only\}

* Zhang W, Sun D, Li W, Wei X. Clinical observation of efficacy of Ganoderm Lucidum capsule on induced toxicity of radiotherapy/chemotherapy. Journal of Binzhou Medical College 1999;22(2):141-2.

Zhou 2001 \{published data only\}

Zhou J, Zou XX, Zhou JC. Clinical investigation of Lingzhi infusion in adjuvant treatment of tumour. Jiangxi Journal of Traditional Chinese Medicine 2001;32(3):30-1.

\section{Zhou 2005 \{published data only\}}

Zhou S, Gao Y, Chan E. Clinical trials for medicinal mushrooms: experience with Ganoderma lucidum (W.Curt.:Fr.) Lloyd (Lingzhi mushroom). International Journal of Medicinal Mushrooms 2005;7(1-2):111-7.

\section{Zhuang 2009 \{published data only\}}

* Zhuang SR, Chen SL, Tsai JH, Huang CC, Wu TC, Liu WS, et al. Effect of citronellol and the Chinese medical herb complex on cellular immunity of cancer patients receiving chemotherapy/ radiotherapy. Phytotherapy Research 2009;23(6):785-90.

\section{References to ongoing studies}

Matthew 2010 \{published data only (unpublished sought but not used)\}

Shing MMK. Ling Zhi for cancer children. ClinicalTrials.gov Phase III trial, NCT00575926.

\section{Additional references}

\section{Boh 2007}

Boh B, Berovic M, Zhang J, Zhi-Bin L. Ganoderma lucidum and its pharmaceutically active compounds. Biotechnology Annual Review 2007;13:265-301.

\section{Brittenden 1996}

Brittenden, J, Heys, S. D, Ross, J, Eremin, O. Natural killer cells and cancer. Cancer 1996;77:1226-1243.

\section{Brown 2006}

Brown GD. Dectin-1: a signalling non-TLR pattern recognition receptor. Nature Reviews Immunology 2006;6(1):33-43.

\section{Chan 2005}

Chan WK, Lam DT, Law HK, Wong WT, Koo MV, Lau AS, et al. Ganoderma lucidum mycelium and spore extracts as natural adjuvants for immunotherapy. Journal of Alternative and Complementary Medicine 2005;11(6):1047-57.

\section{Chan 2007}

Chan WK, Law HK, Lin ZB, Lau YL, Chan GC. Response of human dendritic cells to different immunomodulatory polysaccharides derived from mushroom and barley. International Immunology 2007;19(7):891-9. 


\section{Chang 1999}

Chang ST, Buswell JA. Ganoderma lucidum - a mushrooming medicinal mushroom. International Journal of Medicinal Mushroom 1999;1:139-46.

\section{Chinn 2000}

Chinn S. A simple method for converting an odds ratio to effect size for use in meta-analysis. Statistics in Medicine 2000;19(22):3127-31.

\section{CONSORT 2010}

Kenneth F Schulz, Douglas G Altman, David Moher. CONSORT 2010 Statement: updated guidelines for reporting parallel group randomised trials. Annals of Internal Medicine. 15Feb-2011;154(4):290-1.

\section{Flanagan 1982}

Flanagan JC. Measurement of quality of life: current state of the art. Archives of Physical Medicine and Rehabilitation 1982;63:56-9.

\section{Gantner 2003}

Gantner BN, Simmons RM, Canavera SJ, Akira S, Underhill DM. Collaborative induction of inflammatory responses by dectin-1 and toll-like receptor 2. The Journal of Experimental Medicine 2003;197(9):1107-17.

\section{Harbord 2005}

Harbord RM, Egger M, Sterne JAC. A modified test for smallstudy effects in meta-analyses of controlled trials with binary endpoints. Statistics in Medicine 2005;25:3443-57.

\section{Higgins 2003}

Higgins JPT, Thompson SG, Deeks JJ, Altman DG. Measuring Inconsistency in meta-analyses. BMJ 2003;327:557-60.

\section{Higgins 2011}

Higgins JPT, Green S (editors). Cochrane Handbook for Systematic Reviews of Interventions Version 5.0.1 [updated March 2011]. The Cochrane Collaboration, 2011. Available from www.cochrane-handbook.org.

\section{Hong 2004}

Hong F, Yan J, Baran JT, Allendorf DJ, Hansen RD, Ostroff GR, et al. Mechanism by which orally administered beta-1-3glucans enhance the tumoricidal activity of antitumour monoclonal antibodies in murine tumour models. The Journal of Immunology 2004;173(2):797-806.

\section{Jong 1992}

Jong SC, Birmingham JM. Medicinal benefits of the mushroom Ganoderma. Advances in Applied Microbiology 1992;37:101-34.

\section{Lee 1998}

Lee S, Park S, Oh JW, Yang C. Natural inhibitors for protein prenyl transferase. Planta Medica 1998;64:303-8.

\section{Miller 1981}

Miller AB, Hoogstraten B, Staquet M, Winkler A. Reporting results of cancer treatment. Cancer 1981;47:207-14.

\section{Min 2000}

Min BS, Gao JJ, Nakamura N, Hattori M. Triterpenes from the spores of Ganoderma lucidum and their cytotoxicity against Meth-A and LLC tumor cells. Chemical and Pharmaceutical Bulletin 2000;48:1026-33.

\section{ONS 2005}

Oncology Nursing Society (ONS). Chemotherapy and Biotherapy Guidelines and Recommendations for Practice. Oncology Nursing Society, 2005.

\section{Park 2003}

Park JO, Lee SI, Song SY, Kim K, Kim WS, Jung CW, et al. Measuring response in solid tumors: comparison of RECIST and WHO respo Japanese Journal of Clinical Oncology 2003;33(10):533-7.

\section{Patrick 2000}

Patrick T, Arbuck SG, Eisenhauer EA, Wanders J, Kaplan RS, Rubinstein L, et al. New guidelines to evaluate the response to treatment in solid tumors. Journal of the National Cancer Institute 2000;92:205-16.

\section{Steward 2003}

Steward BW, Kleihues P, World Health Organization. World Cancer Report 2003. IARC Press, 2003.

\section{Upton 2000}

Upton R. American Herbal Pharmacopoeia: Reishi Mushroom. American Herbal Pharmacopoeia, 2000.

\section{WHO 1979}

World Health Organization. WHO handbook for reporting results of cancer treatment; Offset Publication No. 48. Geneva (Switzerland): Would Health Organization Offset Publication, 1979.

\section{Zheng 2011}

Sheng Zheng, Yanping Jia, Jun Zhao, Qun Wei, Yuehua Liu. Ganoderma lucidum polysaccharides eradicates the blocking effect of fibrinogen on NK cytotoxicity against melanoma cells. Oncology Letters December 6, 2011;3(3):613-616.

* Indicates the major publication for the study

\section{CHARACTERISTICS OF STUDIES}

Characteristics of included studies [ordered by study ID] 
Gao 2003b (Continued)

\begin{tabular}{ll} 
Participants & 68 patients with histologically confirmed advanced stage (stage III or IV) lung cancer \\
\hline Interventions & Ganopoly vs. placebo \\
\hline Outcomes & $\begin{array}{l}\text { Treatment response (WHO criteria), QoL (Karnofsky score), immune functions (lymphocyte transforma- } \\
\text { tion, NK activity, CD subsets), adverse reactions }\end{array}$
\end{tabular}

\section{Notes}

\section{Risk of bias}

\begin{tabular}{|c|c|c|}
\hline Bias & Authors' judgement & Support for judgement \\
\hline $\begin{array}{l}\text { Random sequence genera- } \\
\text { tion (selection bias) }\end{array}$ & Unclear risk & $\begin{array}{l}\text { Insufficient information regarding the randomisation process was provided in } \\
\text { the text. Size and characteristics of groups are comparable }\end{array}$ \\
\hline $\begin{array}{l}\text { Allocation concealment } \\
\text { (selection bias) }\end{array}$ & Unclear risk & No explicit information of allocation concealment \\
\hline $\begin{array}{l}\text { Blinding (performance } \\
\text { bias and detection bias) } \\
\text { All outcomes }\end{array}$ & Low risk & $\begin{array}{l}\text { Patients and doctors were blinded, a placebo of same shape, colour and size } \\
\text { was used }\end{array}$ \\
\hline $\begin{array}{l}\text { Incomplete outcome data } \\
\text { (attrition bias) } \\
\text { All outcomes }\end{array}$ & Low risk & 8 patients were lost to follow-up ( 5 in treatment group and 3 in placebo group) \\
\hline $\begin{array}{l}\text { Selective reporting (re- } \\
\text { porting bias) }\end{array}$ & Low risk & $\begin{array}{l}\text { Protocol is unavailable from the authors. Based on the publication itself, selec- } \\
\text { tive reporting is unlikely }\end{array}$ \\
\hline Other bias & Low risk & The study seems to be free of other sources of bias \\
\hline
\end{tabular}

He 1997

\begin{tabular}{ll}
\hline Methods & RCT \\
\hline Participants & 160 various cancer patients (100 intervention, 60 control) \\
\hline Interventions & Lingzhi spore powder capsule + chemo/radiotherapy vs. chemo/radiotherapy \\
\hline Outcomes & QoL (Karnofsky score), blood count (WBC, Hb) \\
\hline Notes & Data from only 10 patients are obtained for blood count
\end{tabular}

\section{Risk of bias}

\begin{tabular}{lll}
\hline Bias & Authors' judgement & Support for judgement \\
\hline $\begin{array}{l}\text { Random sequence genera- } \\
\text { tion (selection bias) }\end{array}$ & High risk & $\begin{array}{l}\text { Very limited information about sequence generation. Significant difference in } \\
\text { size between groups suggests randomisation probably is not done }\end{array}$ \\
\hline $\begin{array}{l}\text { Allocation concealment } \\
\text { (selection bias) }\end{array}$ & High risk & No information regarding allocation concealment \\
\hline
\end{tabular}


He 1997 (Continued)
Blinding (performance
High risk
An open trial in which QoL is an outcome of observation
bias and detection bias)

All outcomes

\begin{tabular}{lll}
\hline $\begin{array}{l}\text { Incomplete outcome data } \\
\text { (attrition bias) } \\
\text { All outcomes }\end{array}$ & High risk & $\begin{array}{l}\text { Only } 10 \text { patients were compared for blood count, although no missing data in } \\
\text { assessing QoL }\end{array}$ \\
\hline $\begin{array}{l}\text { Selective reporting (re- } \\
\text { porting bias) }\end{array}$ & High risk & $\begin{array}{l}\text { Investigation in lymphocyte, platelet and immunoglobulins are mentioned in } \\
\text { the Methods but are missing in the Results }\end{array}$ \\
\hline Other bias & High risk & $\begin{array}{l}\text { Significant imbalance between the number of patients of intervention group } \\
\text { and that of control groups }\end{array}$ \\
\hline
\end{tabular}

Leng 2003

\begin{tabular}{ll}
\hline Methods & RCT \\
\hline Participants & 60 patients after colon cancer surgery \\
\hline Interventions & Zhengqing Lingzhi liquid vs. routine therapy \\
\hline Outcomes & T-cell subgroups, clinical symptoms \\
\hline Notes & - \\
\hline
\end{tabular}

\section{Risk of bias}

\begin{tabular}{|c|c|c|}
\hline Bias & Authors' judgement & Support for judgement \\
\hline $\begin{array}{l}\text { Random sequence genera- } \\
\text { tion (selection bias) }\end{array}$ & Unclear risk & Randomisation process is not detailed in the publication \\
\hline $\begin{array}{l}\text { Allocation concealment } \\
\text { (selection bias) }\end{array}$ & Unclear risk & No information of allocation concealment \\
\hline $\begin{array}{l}\text { Blinding (performance } \\
\text { bias and detection bias) } \\
\text { All outcomes }\end{array}$ & Low risk & $\begin{array}{l}\text { An open trial, but no subjective outcome was investigated, hence review au- } \\
\text { thors believe this will not introduce bias }\end{array}$ \\
\hline $\begin{array}{l}\text { Incomplete outcome data } \\
\text { (attrition bias) } \\
\text { All outcomes }\end{array}$ & Low risk & No incomplete outcome data reported \\
\hline $\begin{array}{l}\text { Selective reporting (re- } \\
\text { porting bias) }\end{array}$ & Low risk & $\begin{array}{l}\text { Protocol is unavailable. It is not common that T-cell subsets are the only ob- } \\
\text { servation in a trial of cancer treatment, however review authors do not believe } \\
\text { this would introduce significant bias in the meta-analysis }\end{array}$ \\
\hline Other bias & Low risk & No other sources of bias is found \\
\hline
\end{tabular}

Yan 1998

Methods RCT

Ganoderma lucidum (Reishi mushroom) for cancer treatment (Review) 
Yan 1998 (Continued)

\begin{tabular}{ll} 
Participants & 56 patients non-parvicellular lung cancer \\
\hline Interventions & Laojunxian Lingzhi oral liquid + chemotherapy vs. chemotherapy alone \\
\hline Outcomes & WHO criteria, Karnofsky score, haematological parameters, T-cell subgroups \\
\hline Notes & -
\end{tabular}

\section{Risk of bias}

\begin{tabular}{lll}
\hline Bias & Authors' judgement & Support for judgement \\
\hline $\begin{array}{l}\text { Random sequence genera- } \\
\text { tion (selection bias) }\end{array}$ & Unclear risk & $\begin{array}{l}\text { Sequence generation process is not detailed, simple randomisation may have } \\
\text { been used and results in uneven sample size between arms }\end{array}$ \\
\hline $\begin{array}{l}\text { Allocation concealment } \\
\text { (selection bias) }\end{array}$ & Unclear risk & No explicit information on allocation concealment \\
\hline $\begin{array}{l}\text { Blinding (performance } \\
\text { bias and detection bias) }\end{array}$ & High risk & No blinding was attempted, QoL is likely to be subject to bias \\
\hline $\begin{array}{l}\text { All outcomes } \\
\text { (attrition bias) } \\
\text { All outcomes }\end{array}$ & Low risk & No incomplete outcome data \\
\hline $\begin{array}{l}\text { Selective reporting (re- } \\
\text { porting bias) }\end{array}$ & Low risk & The study protocol is not available, no selective reporting is found in the text \\
\hline \begin{tabular}{l} 
Other bias \\
\hline
\end{tabular} & Low risk & No other sources of bias is found in the text \\
\hline
\end{tabular}

Zhang 2000

\begin{tabular}{|c|c|c|}
\hline Methods & \multicolumn{2}{|l|}{$\mathrm{RCT}$} \\
\hline Participants & \multicolumn{2}{|c|}{29 patients diagnosed as stage III or IV lung cancers } \\
\hline Interventions & \multicolumn{2}{|c|}{ Lingzhi tablet vs. placebo } \\
\hline Outcomes & \multicolumn{2}{|c|}{ Karnofsky score, TNF, sIL-2R, T-cell subgroups, NK activity, haematological parameters } \\
\hline Notes & \multicolumn{2}{|l|}{-} \\
\hline \multicolumn{3}{|l|}{ Risk of bias } \\
\hline Bias & Authors' judgement & Support for judgement \\
\hline $\begin{array}{l}\text { Random sequence genera- } \\
\text { tion (selection bias) }\end{array}$ & High risk & Sequence generated by enrolment order \\
\hline $\begin{array}{l}\text { Allocation concealment } \\
\text { (selection bias) }\end{array}$ & High risk & $\begin{array}{l}\text { No explicit information of allocation concealment. Given an inappropriate ran- } \\
\text { dom sequence generation, review authors believe it would introduce consider- } \\
\text { able selection bias }\end{array}$ \\
\hline
\end{tabular}


Zhang 2000 (Continued)
Blinding (performance
Low risk
A placebo is specifically designed to achieve blinding
bias and detection bias)

All outcomes

\begin{tabular}{lll}
\hline $\begin{array}{l}\text { Incomplete outcome data } \\
\text { (attrition bias) } \\
\text { All outcomes }\end{array}$ & Low risk & Each arm has 2 subjects lost to follow-up \\
\hline $\begin{array}{l}\text { Selective reporting (re- } \\
\text { porting bias) }\end{array}$ & Low risk & The study protocol is not available, no selective reporting in the text \\
\hline Other bias & Low risk & No other sources of bias is found
\end{tabular}

Hb: haemoglobin; NK: natural killer; QoL: quality of life; RCT: randomised controlled trial; sIL-2R: soluble interleukin-2 receptor; TNF: tumour necrosis factor; WBC: white blood cell; WHO: World Health Organization.

\section{Characteristics of excluded studies [ordered by study ID]}

\begin{tabular}{|c|c|}
\hline Study & Reason for exclusion \\
\hline Chen 2006 & Non-randomised \\
\hline Gao 2003a & Non-randomised, non-controlled, before-after study \\
\hline Gao 2004 & Review \\
\hline Gao 2005a & Non-randomised, non-controlled, before-after study \\
\hline Gao 2005b & Non-randomised, open-labelled trial \\
\hline Gill 2008 & Non-randomised trial \\
\hline Huang 2001 & No outcome of interest \\
\hline Jia 2005 & Non-randomised trial \\
\hline Jing 2007 & Intervention consists of multiple herbal ingredients \\
\hline Kuang 2007 & $\begin{array}{l}\text { This study may be a fraud. } 56 \text { patients were allegedly randomised into } 2 \text { equal groups (each group } \\
\text { should have } 28 \text { cases), however we found } 39 \text { cases in the experiment group and } 17 \text { cases in the con- } \\
\text { trol group. In spite of this, the trialists still used } 28 \text { as a denominator in all the data analyses }\end{array}$ \\
\hline Li 2000 & Do not have outcomes of interest \\
\hline Liang 2002 & Intervention consists of multiple herbal ingredients \\
\hline Ma 2003 & Intervention consists of multiple herbal ingredients \\
\hline Mahajna 2009 & Review \\
\hline Mo 1999 & Intervention consists of multiple herbal ingredients \\
\hline Niu 2002 & Case report \\
\hline Pan 2007 & Intervention consists of multiple herbal ingredients \\
\hline
\end{tabular}




\begin{tabular}{|c|c|}
\hline Study & Reason for exclusion \\
\hline Qi 1999 & Non-randomised trial \\
\hline Simerpal 2008 & Non-randomised trial \\
\hline Sliva 2003 & Review \\
\hline Sliva 2006 & Review \\
\hline Song 2006 & Use of G. capense instead of G. lucidum \\
\hline Wang 1999 & Non-randomised trial \\
\hline Wang 2005 & $\begin{array}{l}\text { Does not have outcome of interest: it is a nursing study that observed side effects of chemotherapy } \\
\text { (phlebitis and irritation sign of bladder) }\end{array}$ \\
\hline Xu 2000 & Case report \\
\hline Yuen 2005 & Review \\
\hline Zhang 1999 & Intervention consists of multiple herbal ingredients \\
\hline Zhou 2001 & Non-randomised trial \\
\hline Zhou 2005 & Review \\
\hline Zhuang 2009 & Intervention consists of multiple herbal ingredients \\
\hline
\end{tabular}

Characteristics of ongoing studies [ordered by study ID]

\begin{tabular}{ll}
\hline Matthew $\mathbf{2 0 1 0}$ & $\begin{array}{l}\text { A randomised, double-blind, placebo-controlled, parallel study of the clinical effects of Ganoderma } \\
\text { lucidum (Ling Zhi) in children with cancer }\end{array}$ \\
\hline Methods & Randomised, double-blind, placebo-controlled, parallel study \\
\hline Participants & Target sample size: 58 \\
\hline Interventions & Lingzhi capsule \\
\hline Outcomes & $\begin{array}{l}\text { Generic and cancer-specific paediatric QoL assessment; cellular immune functions; blood counts } \\
\text { and biochemistry for patient safety; infection-related morbidities; overall and event-free survival }\end{array}$ \\
\hline Starting date & September 2002 \\
\hline Contact information & $\begin{array}{l}\text { Matthew MK Shing, MBBS, FRCP, Department of Pediatrics, Prince of Wales Hospital, The Chinese } \\
\text { University of Hong Kong }\end{array}$ \\
\hline Notes & Trialist was contacted, however, was not willing to disclose any data \\
\hline
\end{tabular}

QoL: quality of life 
DATA AND ANALYSES

Comparison 1. Treatment response

\begin{tabular}{lllll}
\hline Outcome or subgroup title & No. of studies & $\begin{array}{l}\text { No. of partici- } \\
\text { pants }\end{array}$ & Statistical method & Effect size \\
\hline 1 WHO criteria & 3 & 153 & Risk Ratio (IV, Fixed, 95\% Cl) & $1.50[0.90,2.51]$ \\
\hline
\end{tabular}

Analysis 1.1. Comparison 1 Treatment response, Outcome 1 WHO criteria.

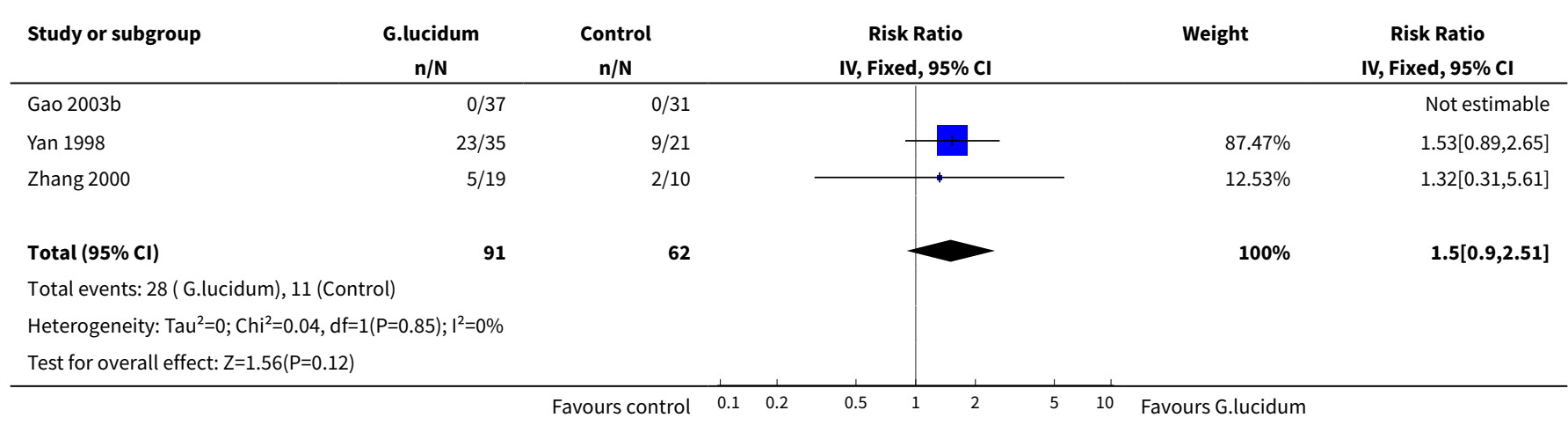

\section{Comparison 2. Host immune functions}

\begin{tabular}{lllll}
\hline $\begin{array}{l}\text { Outcome or } \\
\text { subgroup title }\end{array}$ & No. of studies & $\begin{array}{l}\text { No. of partici- } \\
\text { pants }\end{array}$ & Statistical method & Effect size \\
\hline 1 Leukocyte & 1 & 56 & Mean Difference (IV, Random, 95\% Cl) & $1.52[0.59,2.45]$ \\
\hline 2 NK activity & 2 & 89 & Std. Mean Difference (IV, Random, 95\% Cl) & $0.45[-1.60,2.50]$ \\
\hline 3 CD3 & 4 & 213 & Mean Difference (IV, Fixed, 95\% Cl) & $3.91[1.92,5.90]$ \\
\hline 4 CD4 & 4 & 213 & Mean Difference (IV, Fixed, 95\% Cl) & $3.05[1.00,5.11]$ \\
\hline 5 CD8 & 4 & 213 & Mean Difference (IV, Fixed, 95\% CI) & $2.02[0.21,3.84]$ \\
\hline 6 CD4/CD8 & 4 & 213 & Mean Difference (IV, Fixed, 95\% CI) & $0.12[0.01,0.23]$
\end{tabular}

Analysis 2.1. Comparison 2 Host immune functions, Outcome 1 Leukocyte.

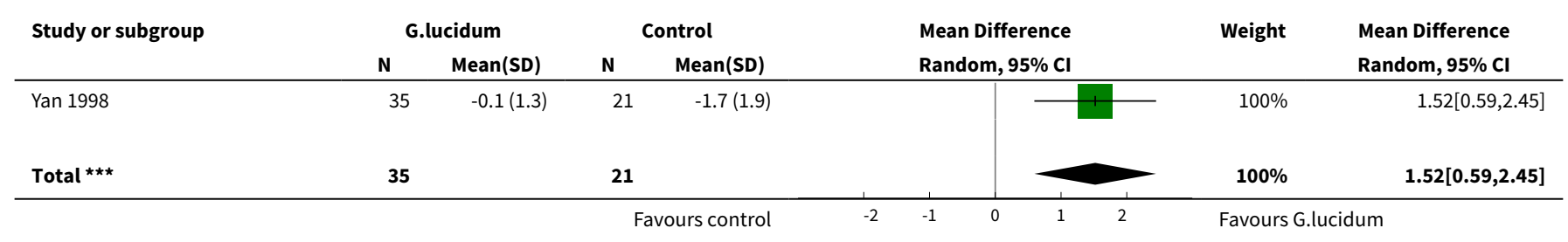




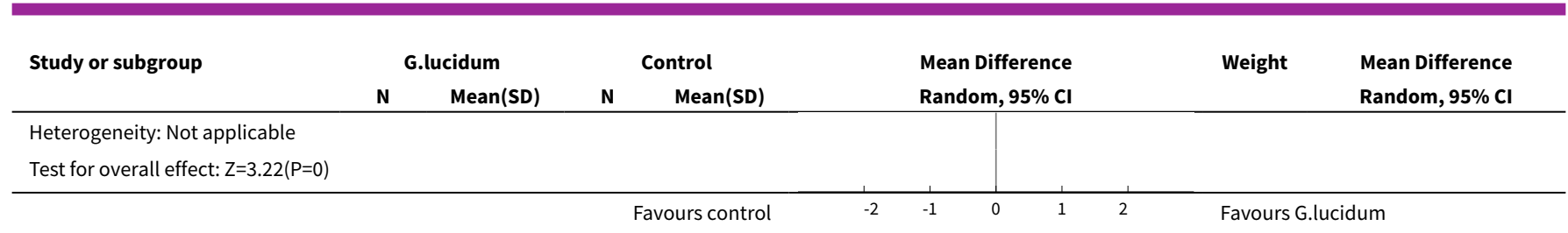

Analysis 2.2. Comparison 2 Host immune functions, Outcome 2 NK activity.

\begin{tabular}{|c|c|c|c|c|c|c|c|c|}
\hline \multirow{3}{*}{$\begin{array}{l}\text { Study or subgroup } \\
\text { Gao 2003b }\end{array}$} & \multicolumn{2}{|c|}{ G.lucidum } & \multicolumn{2}{|c|}{ Control } & \multirow{2}{*}{\multicolumn{2}{|c|}{$\begin{array}{c}\text { Std. Mean Difference } \\
\text { Random, } 95 \% \mathrm{Cl}\end{array}$}} & \multirow[t]{2}{*}{ Weight } & \multirow{2}{*}{$\begin{array}{c}\text { Std. Mean Difference } \\
\text { Random, } 95 \% \mathrm{Cl}\end{array}$} \\
\hline & $\mathbf{N}$ & Mean(SD) & $\mathbf{N}$ & Mean(SD) & & & & \\
\hline & 32 & $18.7(17.2)$ & 28 & $-2.6(9.6)$ & & + & $50.84 \%$ & $1.48[0.9,2.06]$ \\
\hline Zhang 2000 & 19 & $-2.2(6.1)$ & 10 & $1.4(4.8)$ & ب & & $49.16 \%$ & $-0.61[-1.4,0.17]$ \\
\hline 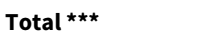 & 51 & & 38 & & & & $100 \%$ & $0.45[-1.6,2.5]$ \\
\hline \multicolumn{9}{|c|}{ Heterogeneity: $\operatorname{Tau}^{2}=2.07 ; \mathrm{Chi}^{2}=17.78, \mathrm{df}=1(\mathrm{P}<0.0001) ; \mathrm{I}^{2}=94.38 \%$} \\
\hline
\end{tabular}

Analysis 2.3. Comparison 2 Host immune functions, Outcome 3 CD3.

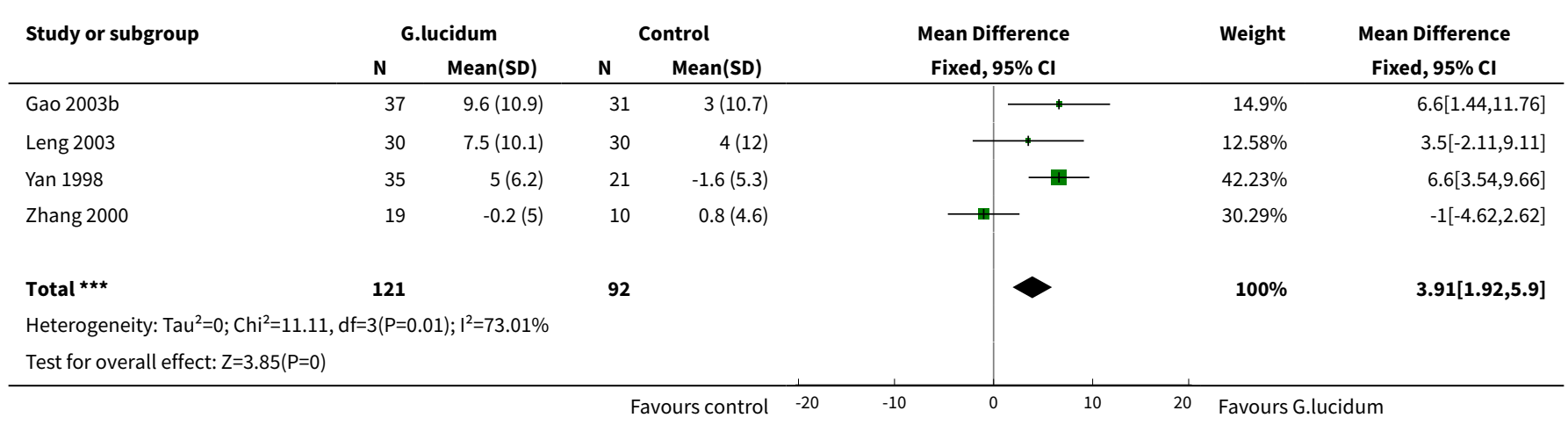

Analysis 2.4. Comparison 2 Host immune functions, Outcome 4 CD4.

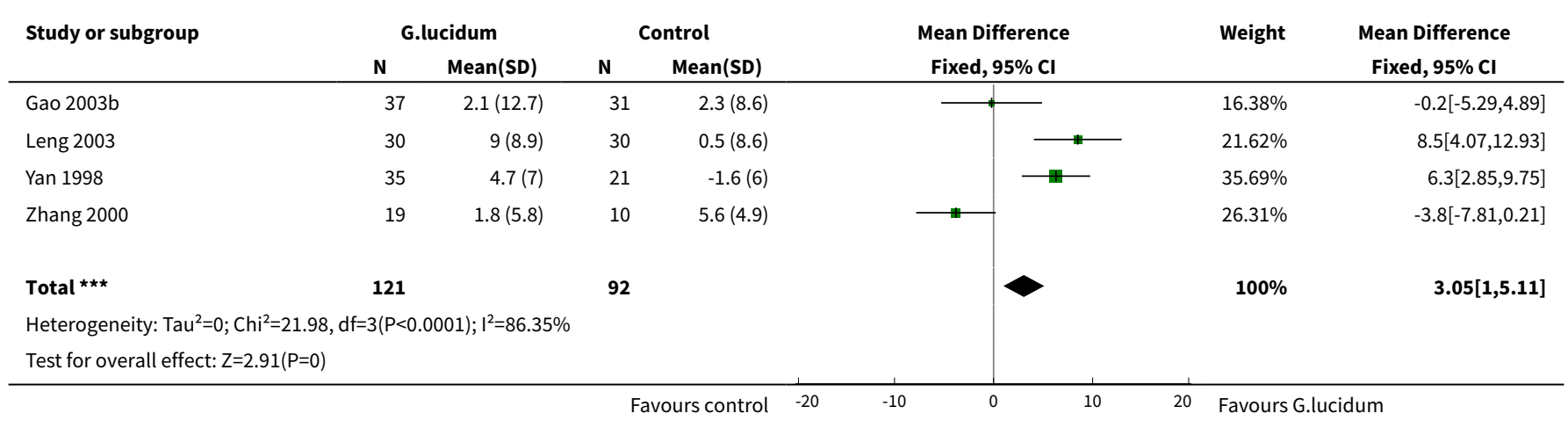


Analysis 2.5. Comparison 2 Host immune functions, Outcome 5 CD8.

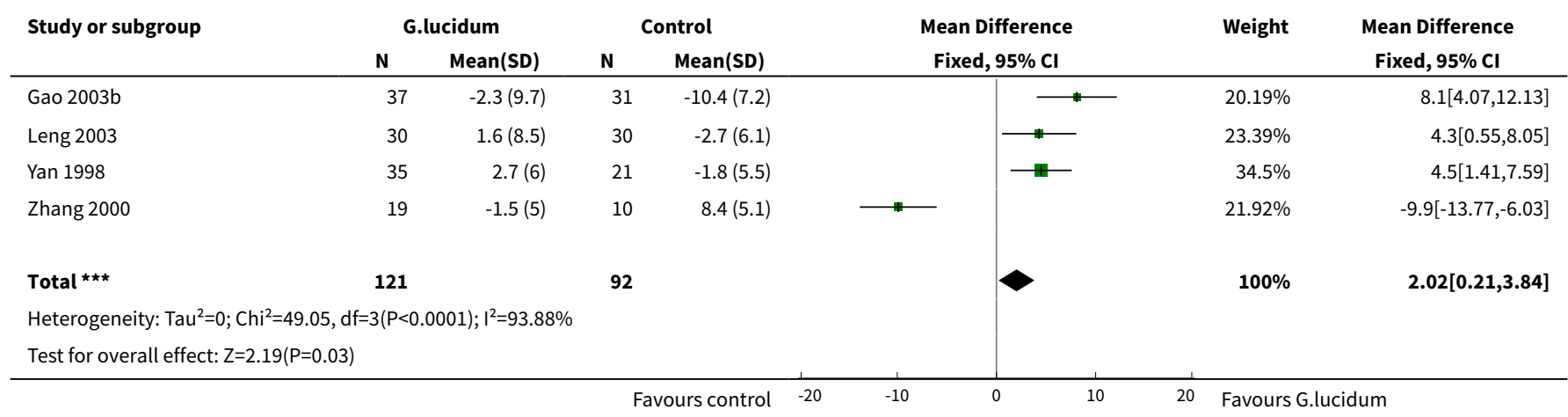

Analysis 2.6. Comparison 2 Host immune functions, Outcome 6 CD4/CD8.

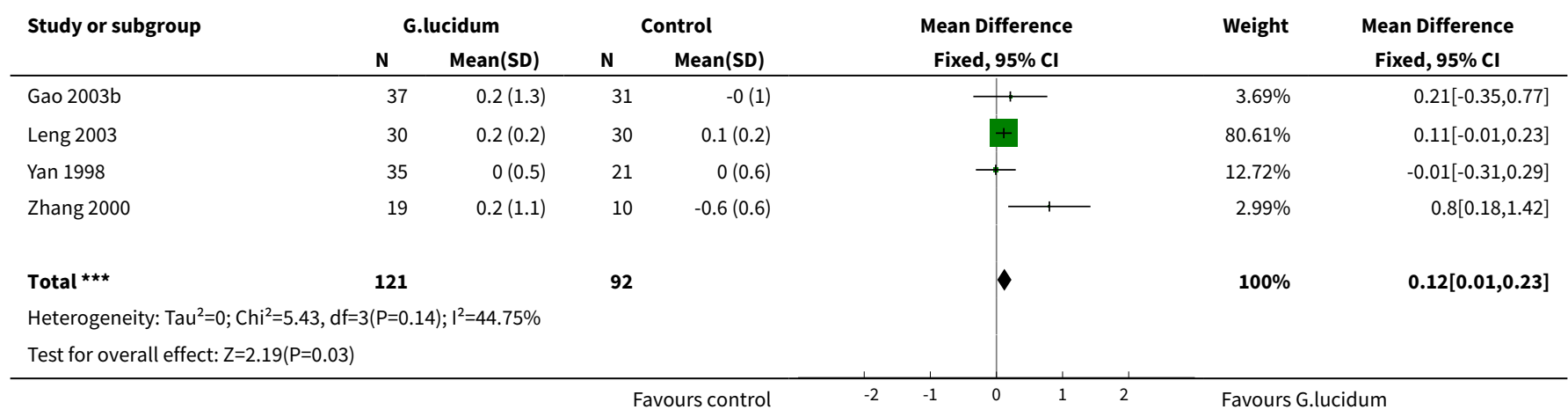

\section{Comparison 3. Quality of life}

\begin{tabular}{lllll}
\hline Outcome or subgroup title & No. of studies & $\begin{array}{l}\text { No. of partici- } \\
\text { pants }\end{array}$ & Statistical method & Effect size \\
\hline $\begin{array}{l}1 \text { Karnofsky score (dichoto- } \\
\text { mous)) }\end{array}$ & 3 & 284 & Risk Ratio (IV, Fixed, 95\% CI) & $2.51[1.86,3.40]$ \\
\hline 2 Karnofsky score & 1 & 29 & $\begin{array}{l}\text { Mean Difference (IV, Fixed, 95\% } \\
\text { Cl) }\end{array}$ & $12.70[-4.72,30.12]$ \\
\hline
\end{tabular}

Analysis 3.1. Comparison 3 Quality of life, Outcome 1 Karnofsky score (dichotomous)).

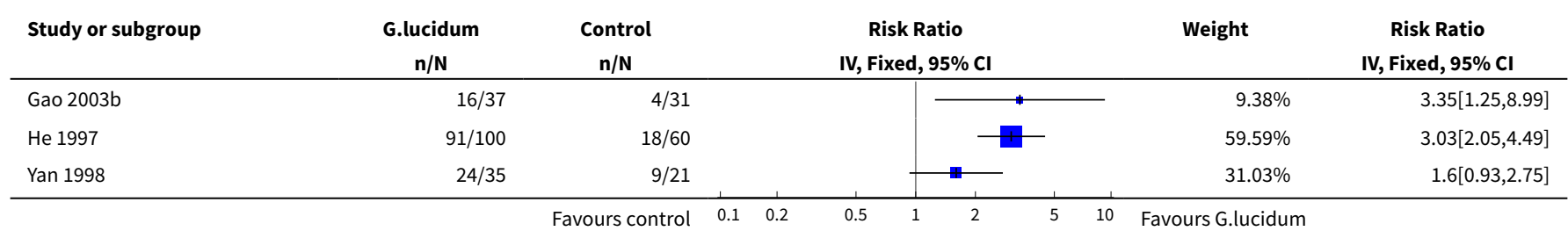




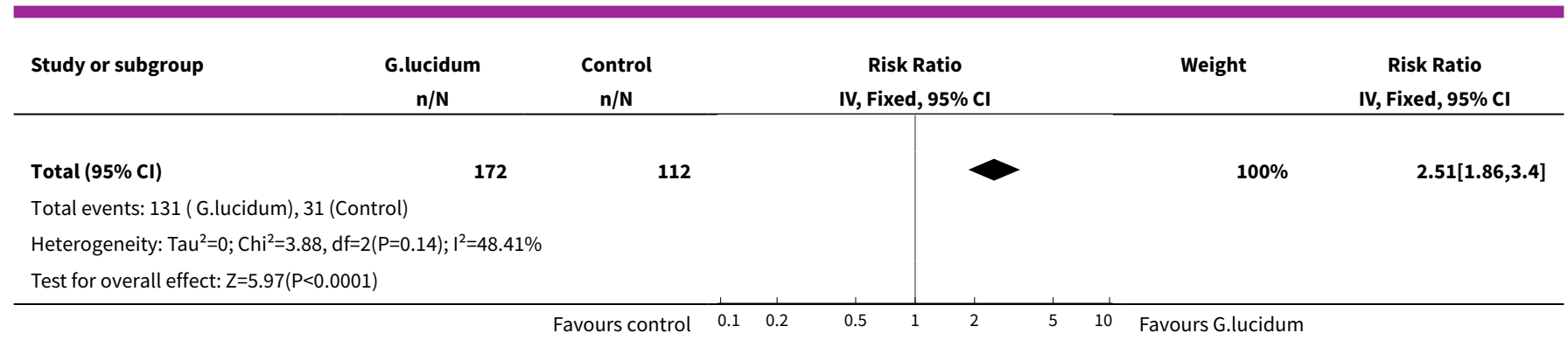

Analysis 3.2. Comparison 3 Quality of life, Outcome 2 Karnofsky score.

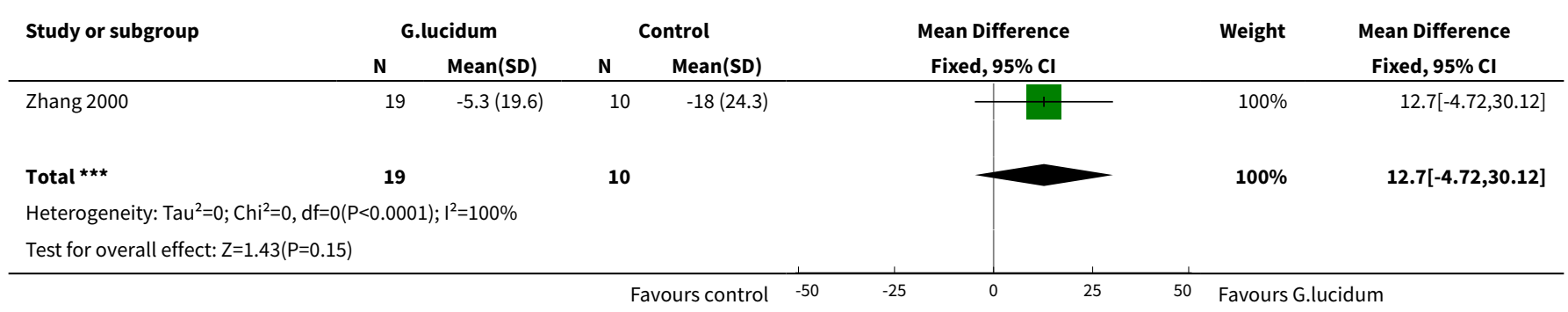

\section{ADDITIONAL TABLES}

Table 1. Intervention combinations

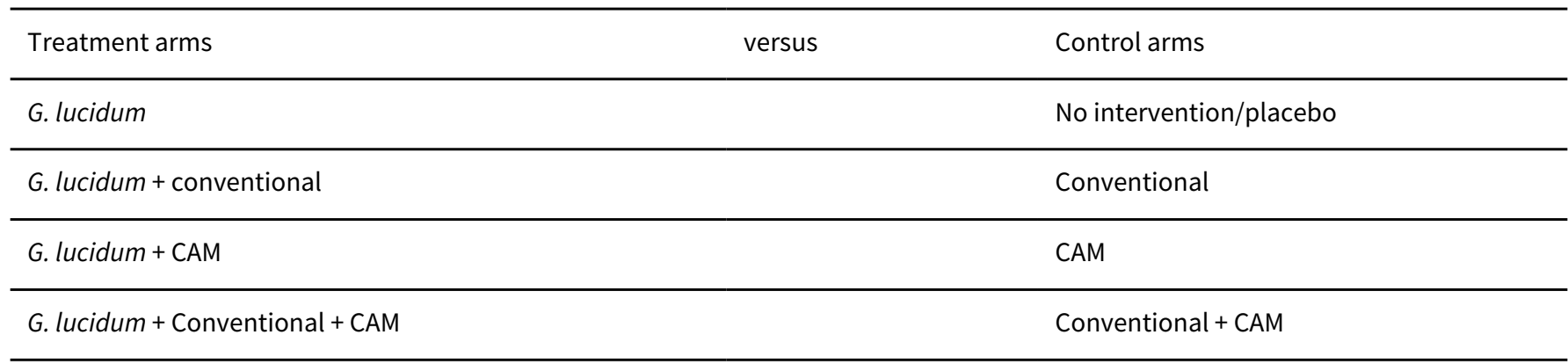

CAM: complementary and alternative medicine

\section{APPEN DICES}

\section{Appendix 1. CENTRAL search strategy}

\#1 MeSH descriptor Neoplasms explode all trees

\#2 (cancer* or carcinoma* or adenocarcinoma* or neoplasm ${ }^{\star}$ or tumor ${ }^{\star}$ or tumour ${ }^{\star}$ or malignan ${ }^{\star}$ ).mp.

\#3 \#1 or \#2

\#4 MeSH descriptor Ganoderma explode all trees

\#5 (ganoderma* or lucidum* or reishi* or lingzhi* or ling zhi* or ling chih or ling chi ${ }^{\star}$ ).mp.

\#6 \#4 or \#5

$\# 7$ \#3 and \#6

\section{Appendix 2. MEDLINE search strategy}

1 exp ganoderma/ 


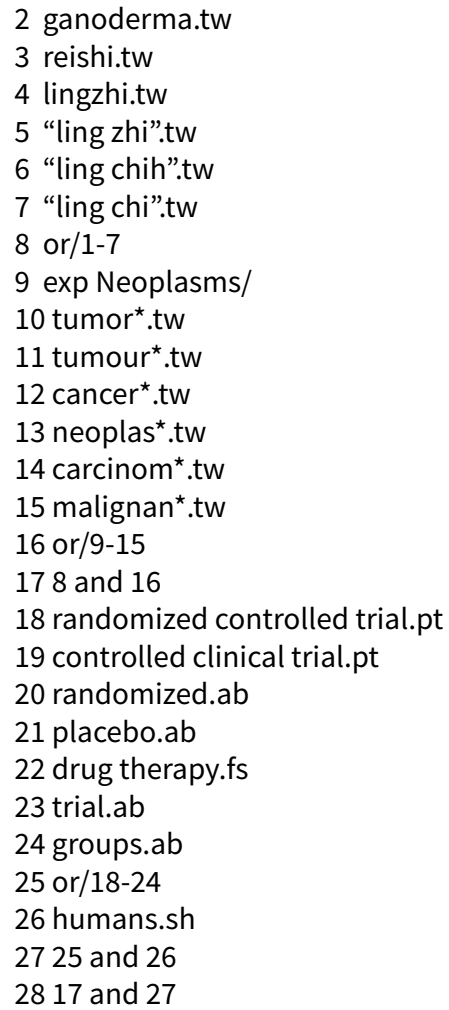

\section{Appendix 3. EMBASE search strategy}

1. exp Ganoderma/

2. exp Ganoderma lucidum/

3. (ganoderma* or lucidum* or reishi* or lingzhi* or ling zhi* or ling chih or ling chi^).mp.

4. 1 or 2 or 3

5. exp neoplasm/

6. (cancer ${ }^{\star}$ or carcinoma ${ }^{\star}$ or adenocarcinoma ${ }^{\star}$ or neoplasm ${ }^{\star}$ or tumor ${ }^{\star}$ or tumour ${ }^{\star}$ or $_{\text {malignan }}$ ).mp.

7.5 or 6

8.4 and 7

9. crossover procedure/

10. double-blind procedure/

11. randomized controlled trial/

12. single-blind procedure/

13. random*.mp.

14. factorial ${ }^{\star} . \mathrm{mp}$

15. (crossover ${ }^{\star}$ or cross over ${ }^{\star}$ or cross-over $\left.^{\star}\right) . \mathrm{mp}$.

16. placebo*.mp.

17. (double* adj blind $\left.{ }^{\star}\right) \cdot m p$.

18. $\left(\right.$ singl ${ }^{\star}$ adj blind $\left.{ }^{\star}\right) \cdot m p$.

19. assign ${ }^{\star} . \mathrm{mp}$.

20. allocat*.mp.

21. volunteer ${ }^{\star} . \mathrm{mp}$.

22.9 or 10 or 11 or 12 or 13 or 14 or 15 or 16 or 17 or 18 or 19 or 20 or 21

23. 8 and 22

\section{Key:}

$\mathrm{mp}=$ title, abstract, original title, name of substance word, subject heading word, protocol supplementary concept, rare disease supplementary concept, unique identifier

$\mathrm{pt}=$ publication type

$a b=a b s t r a c t$

sh=subject heading

ti=title 


\section{Appendix 4. I/O form for primary studies}

\section{I/O form for Primary Studies}

Study ID:

Reviewer:

Date:

\section{Identification Details:}

Author:

Year:

Journal Reference:

Source:

Digital Object Identifier (DOI):

On EndNote database: Yes/ No

\section{Selection Criteria:}

1. Study design is a RCT, not other designs...................................................... Yes/ No

2. The study concerns individual diagnosed with cancer..........................................es/ No

3. The study concerns Ganoderma Lucidum treatment........................................... Yes/ No

4. The study concerns at least one of following outcomes.................................... Yes/ No

(Antitumor response/ immune system/ quality of life/ survival/ mortality/ adverse event)

Please tick only one box:

In Out Pending

\section{Appendix 5. Standard extraction form for included studies}

\section{Study ID:}

Reviewer:

Date:

\section{General Information:}

Authors:

Year: 
Published: ...Yes/No

Title:

Journal Reference:

Publication Type:.. Full text/ Abstract

Language:. English/Chinese/ Japanese/ others

Funding Source:

Author can be contacted for accessible data... .. Yes/ No

General information free text:

\section{Design Details:}

\subsection{Population:}

Target Population:

Study Setting:

Total No. of Participants:

Cancer Type:

Cancer Stage:

Diagnostic Criteria:

Inclusion and Exclusion Criteria:

\subsection{Interventions and Comparators:}

No. of arms in this study:

G. lucidum details (manufacturer, preparation, and dose):

Interventions in experimental arm:

Interventions in control arms: 
Free text comments on interventions:

\subsection{Outcomes:}

Outcomes measured:

Tumour response. .Yes/ No

Immune functions:

T lymphocytes...................................................es/ No

B lymphocytes................................................ Yes/ No

Macrophages................................................Yes/ No

NK cell activity..................................................es/ No

Interleukins....................................................Yes/ No

TNF. ..Yes/ No

Quality of life..... ...Yes/ No

Survival/ Mortality. ....Yes/ No

Side effects. Yes/ No

Others:

Comments on outcomes measured:

\section{Data and Analysis}

Statistical method for data analysis:

Subject data:

Intervention Group

Control Group

No. Pre-specified

\section{No. Assigned}

$\%$ of Males

Mean Age

Median Age

No. Withdrawal from Baseline 
(Continued)

No. Loss to Follow-up

No. Analyzed for Outcome Measure

Outcome data:

Intervention Group Control Group

Primary Outcomes:

Secondary Outcomes

(eg. Dichotomous data: 29/ 89; Continuous data: $89 \pm 12$ unit)

Comments on data analysis:

\section{Appendix 6. Risk of bias assessment form for included studies}

Study ID:

Reviewer:

Date:

\begin{tabular}{ll}
\hline Adequate Sequence Generation: & Judgement \\
\hline Allocation Concealment: & Description \\
\hline Adequate Binding: &
\end{tabular}


(Continued)

Incomplete Outcome Data Addressed:

\section{Selective Outcome Reporting:}

\section{Free of Other Bias:}

\section{Summary of Bias:}

\section{Appendix 7. Criteria for judging risk of bias}

\section{Adequate sequence generation}

Criteria for a judgement of "Yes":

The investigators describe a random component in the sequence generation process such as:

- referring to a random number table,

- using a computer random number generator,

- coin tossing,

- shuffling cards or envelopes,

- throwing dice,

- drawing of lots,

- minimisation.

Criteria for a judgement of "No":

Sequence generation process involves some systematic, non-random approach, for example:

- sequence generated by odd or even date of birth,

- sequence generated by some rule based on date (or day) of admission,

- sequence generated by some rule based on hospital or clinic record number.

Sequence generation process involves judgement or some method of non-random categorisation of participants, for example:

- allocation by judgement of the clinician,

- allocation by preference of the participant,

- allocation based on the results of a laboratory test or a series of tests,

- allocation by availability of the intervention.

Criteria for a judgement of "Unclear":

Insufficient information about sequence generation process

\section{Allocation concealment}

Criteria for a judgement of "Yes":

Participants and investigators enrolling participants could not foresee assignment because a successful method of allocation concealment, for example:

- central allocation (including telephone, web-based, and pharmacy-controlled, randomisation),

- sequentially numbered drug containers of identical appearance,

- sequentially numbered, opaque, sealed envelopes.

Criteria for a judgement of "No":

Participants and investigator enrolling participants could possibly foresee assignments and thus introduce selection bias, for example:

- using an open random allocation schedule (e.g. a list of random numbers), 
- assignment envelopes were used without appropriate safeguards (e.g. if envelopes were unsealed or non-opaque or not sequentially numbered),

- alternation or rotation,

- date of birth,

- case record number,

- any other explicitly unconcealed procedure.

Criteria for a judgement of "Unclear":

Insufficient detail to permit judgement of "Yes" or "No".

\section{Adequate binding}

Criteria for a judgement of "Yes":

Any one of the following:

- no blinding, but the review authors judge that the outcome and the outcome measurement are not likely to be influenced by lack of blinding,

- blinding of participants and key study personnel ensured, and unlikely that the blinding could have been broken,

- either participants or some key study personnel were not blinded, but outcome assessment was blinded and the non-blinding of others unlikely to introduce bias.

Criteria for a judgement of "No":

Any one of the following:

- no blinding or incomplete blinding, and the outcome or outcome measurement is likely to be influenced by lack of blinding,

- blinding of key study participants and personnel attempted, but likely that the blinding could have been broken,

- either participants or some key study personnel were not blinded, and the non-blinding of others likely to introduce bias.

Criteria for a judgement of "Unclear":

Any one of the following:

- insufficient information to permit judgement of "Yes" or "No",

- the study did not address this outcome.

\section{Incomplete outcome data addressed}

Criteria for a judgement of "Yes":

Any one of the following:

- no missing outcome data,

- reasons for missing outcome data unlikely to be related to true outcome (for survival data, censoring unlikely to be introducing bias),

- missing outcome data balanced in numbers across intervention groups, with similar reasons for missing data across groups,

- for dichotomous outcome data, the proportion of missing outcomes compared with observed event risk not enough to have a clinically relevant impact on the intervention effect estimate,

- for continuous outcome data, plausible effect size (difference in means or standardized difference in means) among missing outcomes not enough to have a clinically relevant impact on observed effect size,

- missing data have been imputed using appropriate methods.

Criteria for a judgement of "No":

Any one of the following:

- reason for missing outcome data likely to be related to true outcome, with either imbalance in numbers or reasons for missing data across intervention groups,

- for dichotomous outcome data, the proportion of missing outcomes compared with observed event risk enough to induce clinically relevant bias in intervention effect estimate,

- for continuous outcome data, plausible effect size (difference in means or standardized difference in means) among missing outcomes enough to induce clinically relevant bias in observed effect size, 
- 'as-treated' analysis done with substantial departure of the intervention received from that assigned at randomisation,

- potentially inappropriate application of simple imputation.

Criteria for a judgement of "Unclear":

- insufficient reporting of attrition/exclusions to permit judgement of "Yes" or "No",

- the study did not address this outcome.

\section{Selective outcome reporting:}

Criteria for a judgement of "Yes":

Any of the following:

- the study protocol is available and all of the study's prespecified (primary and secondary) outcomes that are of interest in the review have been reported in the prespecified way,

- the study protocol is not available but it is clear that the published reports include all expected outcomes, including those that were prespecified (convincing text of this nature may be uncommon)

Criteria for a judgement of "No":

Any one of the following:

- not all of the study's prespecified primary outcomes have been reported,

- one or more primary outcomes is reported using measurements, analysis methods or subsets of the data (e.g. subscales) that were not prespecified,

- one or more reported primary outcomes were not prespecified (unless clear justification for their reporting is provided, such as an unexpected adverse effect),

- one or more outcomes of interest in the review are reported incompletely so that they cannot be entered in a meta-analysis,

- the study report fails to include results for a key outcome that would be expected to have been reported for such a study.

Criteria for a judgement of "Unclear":

Insufficient information to permit judgement of "Yes" or "No".

\section{Free of other bias:}

Criteria for a judgement of "Yes":

The study appears to be free of other sources of bias.

Criteria for a judgement of "No":

- there is at least one important risk of bias. For example, the study,

- had a potential source of bias related to the specific study design used, or

- stopped early due to some data-dependent process (including a formal-stopping rule), or

- had extreme baseline imbalance, or

- has been claimed to have been fraudulent, or

- had some other problem.

Criteria for a judgement of "Unclear":

There may be a risk of bias, but there is either:

- insufficient information to assess whether an important risk of bias exists, or

- insufficient rationale or evidence that an identified problem will introduce bias

\section{Summary of bias:}

A - low risk of bias:

All criteria above met.

$B$ - moderate risk of bias: 
One or more or criteria only partly met.

\section{C - high risk of bias}

One or more criteria not met.

\section{WHAT'S NEW}

\begin{tabular}{lll}
\hline Date & Event & Description \\
\hline 14 January 2019 & Review declared as stable & $\begin{array}{l}\text { No potentially relevant new studies identified after a scoping } \\
\text { search (January 2019). The conclusions of this Cochrane Review } \\
\text { are therefore still considered up to date. }\end{array}$ \\
& & \\
\hline
\end{tabular}

\section{HISTORY}

Protocol first published: Issue 2, 2009

Review first published: Issue 6, 2012

\begin{tabular}{lll}
\hline Date & Event & Description \\
\hline 3 March 2016 & $\begin{array}{l}\text { New citation required but conclusions } \\
\text { have not changed }\end{array}$ & No new studies were identified for inclusion. \\
\hline 3 March 2016 & New search has been performed & Searches were updated in February 2016. \\
\hline 23 February 2010 & Amended & $\begin{array}{l}\text { 1. WHO Criteria for Tumour Response was added in the Prima- } \\
\text { ry Outcomes, as an alternative to RECIST. The WHO criteria were } \\
\text { frequently used in studies published by 2000. } \\
\text { 2. Details of handling treatment response data added in the } \\
\text { 'Measures of treatment effect'. }\end{array}$ \\
\hline
\end{tabular}

\section{CONTRIBUTIONS OF AUTHORS}

Xingzhong Jin: co-drafting the protocol and review, searching clinical trials, selection of trials, assessing quality of trials, data interpretation. Julieta Ruiz Beguerie: co-drafting the protocol and review, searching clinical trials, selection of trials, assessing quality of trials, data interpretation.

Daniel Man-yeun Sze: searching and translating Chinese trials.

Godfrey CF Chan: co-drafting the protocol and review.

\section{DECLARATIONS OF INTEREST}

None of the authors is involved in clinical trials or have direct financial interest in the subject matter of this review.

\section{SOURCES OF SUPPORT}

\section{Internal sources}

- None, Other.

\section{External sources}

- None, Other. 


\section{DIFFERENCES BETWEEN PROTOCOLAND REVIEW}

The WHO criteria for tumour response assessment was not included in the protocol and was added in the review stage, because it was used in the trials that were conducted prior to the publication of the RECIST.

In the protocol, we predefined a strategy to cope with situations in which there were both dichotomous and continuous data for the same single outcome of interest. We planned to convert the dichotomous data into continuous data by using the method introduced in Section 9.4.6 of the Cochrane Handbook for Systematic Review of Interventions (Higgins 2011). During the review process, we were concerned that combining two different types of data could misinterpret even biased results, thus we presented results pooled from each type of data separately instead.

\section{N DEX TERMS}

\section{Medical Subject Headings (MeSH)}

Antineoplastic Agents [immunology] [ ${ }^{\star}$ therapeutic use]; Immunity, Cellular [immunology]; Neoplasms [ ${ }^{*}$ drug therapy] [immunology] [therapy]; Randomized Controlled Trials as Topic; Reishi [ ${ }^{\star}$ chemistry]

\section{MeSH check words}

Humans 